\title{
The Ambiguity Premium vs. the Risk Premium under Limited Market Participation*
}

\author{
Takashi Ui \\ Faculty of Economics \\ Yokohama National University \\ First Draft: January 2008 \\ This version: April 2010
}

\begin{abstract}
This paper considers a stock market with ambiguity-averse informed investors under the CARA-normal setting, and studies the relationship between limited market participation and the equity premium which is decomposed into the risk premium and the ambiguity premium. In a rational expectations equilibrium, limited market participation arises if the largest deviation of investors' ambiguity increases sufficiently or if the variance of the stock return decreases sufficiently. In each case, a change in the risk premium and a change in the ambiguity premium may have opposite signs. This paper identifies conditions under which a change with the plus sign dominates and thus the equity premium increases when fewer investors participate in the stock market.
\end{abstract}

JEL classification numbers: D81, D82, G12.

Key words: asset price; ambiguity; asymmetric information; rational expectations.

${ }^{*}$ I am very grateful to the referee for many valuable comments. I thank Takao Asano, Hiroshi Fujiki, Masazumi Hattori, Haruo Imai, Atsushi Kajii, Toshihiko Mukoyama, Makoto Saito, Tadashi Sekiguchi, Yutaka Soejima, Norio Takeoka, and seminar participants at Kyoto University, Bank of Japan, Hitotsubashi University, and YNU Nanzan-U finance workshop for valuable comments and discussions. I acknowledge financial support by MEXT, Grant-in-Aid for Scientific Research. 


\section{Introduction}

It is well documented that a large fraction of households do not participate in the stock market even in developed countries. Mankiw and Zeldes (1991) report that only onefourth of U.S. families own stocks, and demonstrate that limited market participation might help explain the equity premium puzzle raised by Mehra and Prescott (1985). The equity premium puzzle refers to the findings that an observed equity premium is too large to be explained by the standard asset pricing models. ${ }^{1}$ The source of the puzzle is that aggregate consumption growth covaries too little with stock returns to justify the large observed equity premium. Mankiw and Zeldes (1991) examine the differences between the consumption patterns of stockholders and non-stockholders, and find that stockholder consumption covaries more strongly with stock returns than does total consumption, ${ }^{2}$ suggesting that the distinction between stockholders and non-stockholders might help explain the equity premium puzzle. Basak and Cuoco (1998) study a theoretical model of limited market participation ${ }^{3}$ which has properties in agreement with the empirical findings of Mankiw and Zeldes (1991). Their model is a continuous-time pure-exchange economy populated by two types of investors, one of which are prevented from investing in the stock market. Using the model, Basak and Cuoco (1998) show that the equity premium increases when fewer investors participate in the stock market.

Cao et al. (2005) and Easley and O'Hara (2009) attribute limited market participation to investors' ambiguity aversion building on the work of Dow and Werlang (1992). ${ }^{4}$ In their model of a stock market, investors have maxmin expected utility preferences axiomatized by Gilboa and Schmeidler (1989); that is, investors have multiple priors for a stock return because they do not have precise information about its probability distribution, and maximize the minimum of expected utility by considering the worst case, where the minimum is taken over the set of priors. More specifically, the stock return is normally distributed with a mean unknown to an investor, and an investor has a CARA utility index function with a set of priors for the stock return, which consists of all normal distributions with means in some fixed interval. Since an investor considers the worst case, the difference between the true mean and the minimum of the interval

\footnotetext{
${ }^{1}$ See Mehra and Prescott (2003) for a survey of the equity premium puzzle.

${ }^{2}$ For related empirical results, see Attanasio et al. (2002), Brav et al. (2002), and Vissing-Jorgensen (2002).

${ }^{3}$ Other theoretical studies of limited market participation include Merten (1987), Balasko et al. (1990, 1995), Cuny (1993), Allen and Gale (1994), and Shapiro (2002) among others.

${ }^{4}$ Since Dow and Werlang (1992) and Epstein and Wang (1994), financial markets under ambiguity have been studied by a growing number of papers, including Epstein and Miao (2003), Uppal and Wang (2003), Liu et al. (2003), Maenhout (2004), and Liu et al. (2005) among others.
} 
represents a degree of investor's ambiguity. This may vary across investors and investors with the lower minimum are deemed confronting higher ambiguity. Cao et al. (2005) and Easley and O'Hara (2009) show that if investors' ambiguity is sufficiently dispersed, then investors with relatively high ambiguity choose not to participate in the stock market, which gives rise to limited market participation. Furthermore, they show that the equity premium under limited market participation can be smaller than that under full market participation, which is opposite to the prediction of Basak and Cuoco (1998) that limited market participation leads to the larger equity premium.

As pointed out by Chen and Epstein (2002) and Cao et al. (2005), the equity premium under ambiguity can be decomposed into two components: the risk premium and the ambiguity premium. ${ }^{5}$ The risk premium corresponds to the equity premium obtained in the standard expected utility models. The ambiguity premium comes from investors' ambiguity aversion and depends upon the average of investors' ambiguity. Cao et al. (2005) argue that, when limited market participation arises, the risk premium increases because fewer investors have to bear all the market risk and demand the larger risk premium, whereas the ambiguity premium decreases because only investors with relatively low ambiguity remain in the stock market and accept the smaller ambiguity premium. In the set-ups of Cao et al. (2005) and Easley and O'Hara (2009), a decrease in the ambiguity premium dominates an increase in the risk premium, which results in a decrease in the equity premium. This result, however, depends upon their specific set-ups: there exist a continuum of uninformed investors and investors' ambiguity is uniformly distributed in Cao et al. (2005) and binominally distributed in Easley and O'Hara (2009).

The purpose of this paper is to elucidate the relationship between the ambiguity premium and the risk premium under limited market participation, and to identify conditions under which limited market participation attributed to investors' ambiguity aversion is compatible with the larger equity premium. Building on the work of Cao et al. (2005), Easley and O'Hara (2009), and Grossman (1976), we consider a model of a stock market under both ambiguity and asymmetric information with a finite number of ambiguity-averse informed investors whose ambiguity profile is arbitrary. By considering arbitrary ambiguity profiles, we can study general situations resulting in limited market participation. By considering informed investors, we can take into account of the following effect of investors' private signals on the risk premium. When an informed investor exits from the stock market, information revealed by private signals diminishes,

\footnotetext{
${ }^{5}$ Epstein and Schneider (2008) theoretically study the relationship between the ambiguity premium and information quality. For empirical studies on the ambiguity premium, seeAnderson et al. (2009) and Erabas and Mirakhor (2007).
} 
and the conditional variance held by participating investors becomes larger. This leads to a larger increase in the risk premium than that when an uninformed investor exits from the stock market. In this paper, we introduce a model and an equilibrium concept capturing the above idea and identify conditions under which the equity premium increases when fewer investors participate in the stock market.

A rational expectations equilibrium is a natural candidate for our equilibrium concept, but the equilibrium price reflects private signals of non-participating investors. ${ }^{6}$ On the other hand, we are interested in a situation where more participating investors bring more information to the market. Hence, we introduce a rational expectations equilibrium with endogenous participation as our equilibrium concept. This is defined as a rational expectations equilibrium restricted to a maximal set of investors satisfying the following conditions: each investor in this set, called a participating investor, receives a private signal and trades non-zero units of the stock; each investor not in this set, called a non-participating investor, does not receive a private signal and trades no stock given the equilibrium price. The maximality of the set implies that even if a non-participating investor received a private signal, he would trade no stock in the rational expectations equilibrium.

We derive the equilibrium in a closed form, where the set of participating investors is uniquely obtained as a solution to some optimization problem. The special case without private signals coincides with the competitive equilibrium studied by Cao et al. (2005) and Easley and O'Hara (2009), and the special case without ambiguity coincides with the rational expectations equilibrium studied by Grossman (1976). We then restrict attention to limited market participation induced by changes in parameters on knowledge or information, and show that limited market participation arises if the largest deviation of investors' ambiguity increases sufficiently, or if the variance of the stock return decreases sufficiently. The former case includes the cases studied by Cao et al. (2005) and Easley and O'Hara (2009). For each case, we derive a necessary and sufficient condition under which the equity premium increases when limited market participation arises.

Our findings show that the equity premium under limited market participation can be larger than that under full market participation provided that the difference between the average ambiguity of participating investors under limited participation and that under full participation is larger than some threshold even without any private signals. Hence, the presence of private signals is not necessary but makes for a more compelling case in favor of a larger equity premium under limited market participation.

\footnotetext{
${ }^{6}$ This type of problem in the notion of rational expectations equilibrium has been pointed out and studied by Kreps (1977) among others.
} 
More precisely, when limited market participation arises by an increase in the largest deviation of investors' ambiguity, the equity premium increases if and only if the difference between the average ambiguity of participating investors under limited market participation and that under full market participation satisfies one of the following conditions: the difference is larger than some threshold, or the difference is larger than another smaller threshold and the variance of private signals is small enough. This result has two simple but important corollaries for the case without private signals. One corollary shows that if the average ambiguity of all investors does not increase when limited market participation arises, then the equity premium decreases. The models of Cao et al. (2005) and Easley and O'Hara (2009) satisfy this condition, explaining why the equity premium decreases in their models. The other corollary shows that if the average ambiguity of investors continuing to participate does not decrease when limited market participation arises, then the equity premium increases. In this case, limited market participation, the larger equity premium, and increased ambiguity coexist.

When the variance of the stock return decreases, the equity premium increases if and only if the variance of private signals is small enough. This is true not only when limited market participation arises but also when it does not. In other words, the smaller variance of the stock return results in the larger equity premium if the variance of private signals is small enough (even when limited market participation does not arise). ${ }^{7}$ This result is in clear contrast to the case without either ambiguity or private signals, where the smaller variance of the stock return results in the smaller equity premium. ${ }^{8}$

Our findings might help understand the role of ambiguity or uncertainty in the market turmoil in the summer of 2007 spread from the US sub-prime mortgage market, which some economists point out. Bernanke (2007) argues:9 "subprime mortgage losses that triggered uncertainty about structured products more generally have reverberated in broader financial markets" and "the resulting global financial losses have far exceeded even the most pessimistic estimates of the credit losses on these loans." Bernanke (2008) also argues: "part of the explanation for the far-reaching financial impact of the subprime shock is that it has contributed to a considerable increase in investor uncertainty about the appropriate valuations of a broader range of financial assets, not just subprime mortgages." For example, on July 19 in 2007, the Dow Jones Industrial Average

\footnotetext{
${ }^{7}$ This result is consistent with the result of Caskey (2009) because, in both results, more information or knowledge results in the larger equity premium.

${ }^{8}$ Easley and O'Hara (2004), Hughes et al. (2007), and Lambert et al. (2006) show that the equity premium decreases in response to increases in the average precision of investors' posteriors.

${ }^{9}$ Roubini (2007) also points out the role of ambiguity or uncertainty in the sub-prime mortgage financial crisis.
} 
closed above 14,000 for the first time, but by August 15, it had dropped below 13,000. Similar drops occurred in virtually every equity market in the world. The associated flight to quality contributed to surges in the demand for short-dated Treasury bills and pushed their rates down sharply, implying fewer investors' participation in risky asset markets. Our findings theoretically explain the coexistence of these anecdotal evidences of increased uncertainty, flight to quality, ${ }^{10}$ and sharply declining risky asset prices.

Financial markets under both ambiguity and asymmetric information ${ }^{11}$ have been studied in the context of the no trade theorem (Milgrom and Stokey, 1982) by Dow et al. (1990), Ma (2001), Wakai (2002), Halevy (2004), and Kajii and Ui (2009) among others. Recently, studies on rational expectations equilibria in such markets started. Tallon (1998) considers a two-agent, two-state economy with asymmetric information and demonstrates that an ambiguity-averse uninformed agent might be willing to pay to acquire a piece of information which is already contained in the equilibrium price. Ozsoylev and Werner (2006) introduce an ambiguity-averse uninformed investor into the model of Grossman and Stiglitz (1980). Condie and Ganguli (2008) consider a general model and demonstrate that a rational expectations equilibrium can be partially revealing over a set of parameters with positive Lebesgue measure. Caskey (2009) adopts the smooth ambiguity aversion model of Klibanoff et al. (2005) and demonstrates that, under a rational expectations equilibrium, the equity premium with a non-sufficient statistic can be smaller than that with a sufficient statistic.

The organization of this paper is as follows. Section 2 introduces the model and the equilibrium concept. Section 3 derives the equilibrium in a closed form. Section 4 provides the main results. Section 5 concludes the paper.

\section{The model}

We consider a market with two assets: a riskless asset and a risky asset. The riskless asset is a numeraire, and a price of the risky asset is denoted by $\tilde{p}$. The total endowment of the risky asset is $z>0 .{ }^{12}$ For each unit purchased, the riskless asset yields a constant return 1 , and the risky asset yields a stochastic return $\tilde{v},{ }^{13}$ which is normally distributed

\footnotetext{
${ }^{10}$ Caballero and Krishnamurthy (2008) and Routledge and Zin (2009) study flight to quality induced by investor's ambiguity aversion.

${ }^{11}$ For other general models with multiple agents under both ambiguity and asymmetric information, see Epstein and Wang (1996), Ahn (2007), and Kajii and Ui (2005).

${ }^{12}$ In order to simplify our analysis, we do not assume a noisy supply of the risky asset. See Remark 4 to Proposition 2.

${ }^{13}$ Throughout this paper, a letter with a tilde refers to a random variable. An equation including random variables is understood in the sense with "almost everywhere" if not otherwise specified.
} 
with mean $\theta$ and variance $1 / \alpha$. The inverse of the variance $\alpha$ is called the precision of $\tilde{v}$. We assume that investors have a precise estimate of the variance of $\tilde{v}$, but do not know exactly the mean of $\tilde{v}$, following Cao et al. (2005). This assumption is motivated by the analytical tractability, the empirical evidence on the predictability of the volatility of stock returns (Bollerslev et al., 1992), and the difficulty in estimating precisely the expected stock returns.

Let $N=\{1, \ldots, n\}$ denote the set of investors. Each investor either participates in the market or not. If investor $i \in N$ participates, he receives a private signal $\tilde{s}_{i} \equiv \tilde{v}+\tilde{\varepsilon}_{i}$, where $\tilde{\varepsilon}_{i}$ is normally distributed with mean 0 and variance $1 / \beta$, and random variables $\tilde{v}, \tilde{\varepsilon}_{1}, \ldots, \tilde{\varepsilon}_{n}$ are independent. Investor $i$ then allocates his initial wealth $w_{0 i}$ between the riskless asset and the risky asset. When investor $i$ purchases $d_{i}$ units of the risky asset at a price $\tilde{p}$, his portfolio yields the return $\tilde{w}_{1 i} \equiv w_{0 i}+(\tilde{v}-\tilde{p}) d_{i}$. If investor $i$ does not participate, he does not receive a private signal and continues to hold his initial wealth $w_{0 i}$. Since each investor observes a price $\tilde{p}$, investor $i$ 's information is $\tilde{I}_{i}=\left(\tilde{s}_{i}, \tilde{p}\right)$ if he participates and $\tilde{I}_{i}=\tilde{p}$ otherwise.

Investor $i \in N$ has a CARA utility index function $u_{i}\left(\tilde{w}_{1 i}\right)=-\exp \left(-\tilde{w}_{1 i} / \gamma_{i}\right)$ with $\gamma_{i}>0$, which induces maxmin expected utility preferences à la Gilboa and Schmeidler (1989) as described below. Investor $i$ does not know $\theta$, but he believes that $\theta$ is contained in an interval $\Theta_{i} \equiv\left[\underline{\theta}_{i}, \bar{\theta}_{i}\right]$. On the other hand, investor $i$ knows $\alpha$ and $\beta$. Thus, investor $i$ knows the way $\theta$ determines the joint distribution of $\tilde{I}_{i}$ and $\tilde{v}$, and uses the conditional expectations operator $E_{\theta^{\prime}}\left[\cdot \mid \tilde{I}_{i}\right]$ for each $\theta^{\prime} \in \Theta_{i}$ to evaluate his portfolio. Investor $i$ is ambiguity averse and evaluates his portfolio in terms of the minimum of expected utility where the minimum is taken over $\Theta_{i}$; that is, the demand for the risky asset of investor $i$ with information $\tilde{I}_{i}$ is

$$
d_{i}\left(\tilde{p} \mid \tilde{I}_{i}\right) \in \arg \max _{d_{i}} \min _{\theta^{\prime} \in \Theta_{i}} E_{\theta^{\prime}}\left[u_{i}\left(w_{0 i}+(\tilde{v}-\tilde{p}) d_{i}\right) \mid \tilde{I}_{i}\right] .
$$

In the above description of preferences, it is assumed that investor $i \in N$ updates each prior in his set of priors $\left\{N\left(\theta^{\prime}, 1 / \alpha\right)\right\}_{\theta^{\prime} \in \Theta_{i}}$ conditional on his information $\tilde{I}_{i}$ to obtain his set of posteriors $\left\{N\left(E_{\theta^{\prime}}\left[\tilde{v} \mid \tilde{I}_{i}\right], V_{\theta^{\prime}}\left[\tilde{v} \mid \tilde{I}_{i}\right]\right)\right\}_{\theta^{\prime} \in \Theta_{i}}$, by which he evaluates his portfolio. This type of updating multiple priors and maxmin expected utility preferences is called the full Bayesian updating. ${ }^{14}$ One of the issues in the full Bayesian updating is a lack of dynamic consistency. ${ }^{15}$ Epstein and Schneider (2003) and Wakai (2002) show that an agent is

\footnotetext{
${ }^{14}$ For papers suggesting, deriving, or characterizing the full Bayesian updating in various settings, see Fagin and Halpern (1990), Wasserman and Kadane (1990), Jaffray (1992), Sarin and Wakker (1998), Pires (2002), Epstein and Schneider (2003), Wang (2003), and Siniscalchi (2006), and Horie (2007) among others.

${ }^{15}$ See Epstein and Le Breton (1993) and Eichberger and Kelsey (1996).
} 
dynamically consistent if his set of priors satisfies a condition called rectangularity. ${ }^{16}$ Kajii and Ui (2009) show that an agent is dynamically consistent if his initial endowment of the risky asset is zero. Our model satisfies the latter condition and thus investors are dynamically consistent.

Concerning the collection of intervals $\left\{\Theta_{i}\right\}_{i \in N}$, we assume that $\bigcap_{i \in N} \Theta_{i} \neq \emptyset$. This assumption is a multiple-priors version of the common prior assumption, ${ }^{17}$ by which we can exclude the possibility of speculative trade. ${ }^{18}$

Note that if every investor knows $\theta$, i.e., $\Theta_{i}=\{\theta\}$ for each $i \in N$, then our model reduces to that of Grossman (1976). Note also that if there is no private signal, i.e., $\beta=0$, then our model reduces to that of Cao et al. (2005) and Easley and O'Hara (2009) with a finite set of investors: Cao et al. (2005) assume a continuum of investors with uniformly distributed $\underline{\theta}_{i}$ and Easley and O'Hara (2009) assume a continuum of investors with binominally distributed $\underline{\theta}_{i}$. In section 4 , simplified finite-investor versions of the models of Easley and O'Hara (2009) and Cao et al. (2005) will be discussed as examples.

Let $M \in 2^{N} \backslash\{\emptyset\}$ be a set of participating investors. A price function for $M$ is a function $p_{M}: \mathbb{R}^{M} \rightarrow \mathbb{R}$ which assigns a price of the risky asset to each realization of a private signal profile of investors in $M, \tilde{s}_{M} \equiv\left(\tilde{s}_{i}\right)_{i \in M}$. The following definition of a rational expectations equilibrium is standard.

Definition 1 A rational expectations equilibrium for $M \in 2^{N} \backslash\{\emptyset\}$ is a price function $p_{M}$ for $M$ such that $\tilde{p}=p_{M}\left(\tilde{s}_{M}\right)$ is a market clearing price; that is,

$$
\sum_{i \in M} d_{i}\left(\tilde{p} \mid \tilde{I}_{i}\right)=z \text { where } \tilde{I}_{i}=\left(\tilde{s}_{i}, \tilde{p}\right) .
$$

We need an equilibrium concept which determines $M$ endogenously. If there is no private signal, there is no need for it: choose $M=N$, find investors who trade non-zero units of the risky asset, and regard them as participating. This is an idea of Cao et al. (2005) and Easley and O'Hara (2009). But if there are private signals, it is not always appropriate to choose $M=N$ for the purpose of this paper because the equilibrium price reflects private signals of non-participating investors. In the following equilibrium concept, we require that an investor receiving a private signal should trade non-zero units of the risky asset and that an investor not receiving a private signal should trade no risky asset, by which market participation is endogenously determined.

\footnotetext{
${ }^{16}$ Based upon Epstein and Schneider (2003), Epstein and Schneider (2007, 2008) study a general model of learning under ambiguity and its applications to financial markets.

${ }^{17}$ See Billot et al. (2000) and Rigotti et al. (2008).

${ }^{18}$ If $\bigcap_{i \in N} \Theta_{i} \neq \emptyset$, then the no trade theorem (Milgrom and Stokey, 1982) holds as shown by Kajii and Ui (2009).
} 
Definition 2 For each $M \in 2^{N} \backslash\{\emptyset\}$, let $p_{M}$ be a rational expectations equilibrium for $M$. A rational expectations equilibrium with endogenous participation given $\left\{p_{M}\right\}_{M \in 2^{N} \backslash\{\emptyset\}}$ is $p_{N^{*}} \in\left\{p_{M}\right\}_{M \in 2^{N} \backslash\{\emptyset\}}$ satisfying the following conditions:

1. If $i \in N^{*}$ and $\tilde{I}_{i}=\left(\tilde{s}_{i}, \tilde{p}\right)$ with $\tilde{p}=p_{N^{*}}\left(\tilde{s}_{N^{*}}\right)$, then $d_{i}\left(\tilde{p} \mid \tilde{I}_{i}\right) \neq 0$.

2. If $i \notin N^{*}$ and $\tilde{I}_{i}=\tilde{p}$ with $\tilde{p}=p_{N^{*}}\left(\tilde{s}_{N^{*}}\right)$, then $d_{i}\left(\tilde{p} \mid \tilde{I}_{i}\right)=0$.

3. For any $M \in 2^{N} \backslash\{\emptyset\}$ with $N^{*} \subsetneq M$, if $i \in M \backslash N^{*}$ and $\tilde{I}_{i}=\left(\tilde{s}_{i}, \tilde{p}\right)$ with $\tilde{p}=p_{M}\left(\tilde{s}_{M}\right)$, then $d_{i}\left(\tilde{p} \mid \tilde{I}_{i}\right)=0$.

Investor $i \in N$ is participating if $i \in N^{*}$ and non-participating otherwise.

We call the case with $N^{*} \subsetneq N$ limited market participation and that with $N^{*}=N$ full market participation.

By the first condition, each participating investor trades non-zero units of the risky asset and the equilibrium price $p_{N^{*}}\left(\tilde{s}_{N^{*}}\right)$ reflects solely such investors' private signals. By the second condition, the equilibrium price is a market clearing price for all investors when participating investors receive private signals and non-participating investors do not. By the third condition, even if a non-participating investor received a private signal, he would trade no risky asset in the rational expectations equilibrium, by which he cannot be a participating investor in the above sense. To justify these conditions, we assume that if an investor is indifferent between an outcome with a private signal and one without a private signal, then he chooses the latter; ${ }^{19}$ that is, if an investor does not expect a strictly positive gain, he does not try to obtain a private signal. The condition that a non-participating investor does not receive a private signal is indispensable for the existence of a market clearing price that depends solely upon private signals of investors trading non-zero units of the risky asset. See Remark 3 to Proposition 2.

It should be noted that if there is no private signal $(\beta=0)$, the third condition does not matter at all. In this case, a rational expectations equilibrium with endogenous participation is reduced to a competitive equilibrium in the standard sense.

We can interpret $p_{N^{*}}$ as a Nash equilibrium of the following game. A strategy set of each investor consists of "to participate" and "not to participate." If an investor chooses to participate, then he receives a private signal, and his payoff is the maxmin expected utility under the rational expectations equilibrium for the set of investors choosing to participate. If an investor chooses not to participate, then he does not receive a private signal, and his payoff is the utility of holding his initial wealth. Suppose that $N^{*}$ is the

${ }^{19}$ Otherwise, people try to obtain all information even if it is useless. 
set of investors choosing to participate. Consider investor $i \in N^{*}$. His payoff is strictly greater than that of holding his initial wealth because he trades non-zero units of the risky asset by the first condition in Definition 2. Thus, investor $i \in N^{*}$ strictly prefers "to participate." Consider investor $i \notin N^{*}$. His payoff is equal to that of holding his initial wealth, and even if he chooses to participate, his payoff is equal to that of holding his initial wealth because he trades no risky asset by the third condition in Definition 2. Therefore, $p_{N^{*}}$ can be interpreted as a Nash equilibrium of the above game. In this game, a player affects the price, but if we consider a continuum of players, he does not. ${ }^{20}$

\section{The equilibrium in a closed form}

In this section, we first obtain a rational expectations equilibrium for each $M \in 2^{N} \backslash\{\emptyset\}$, and then obtain a rational expectations equilibrium with endogenous participation given the collection of the rational expectations equilibria. In so doing, the following function $\Phi: 2^{N} \backslash\{\emptyset\} \rightarrow \mathbb{R}$ plays an important role: for each $M \in 2^{N} \backslash\{\emptyset\}$,

$$
\Phi(M) \equiv \frac{z}{\alpha \sum_{i \in M} \gamma_{i}}+\frac{\sum_{i \in M} \gamma_{i}\left(\theta-\underline{\theta}_{i}\right)}{\sum_{i \in M} \gamma_{i}}=\frac{z}{\alpha \sum_{i \in M} \gamma_{i}}+\frac{\sum_{i \in M} \gamma_{i} \phi_{i}}{\sum_{i \in M} \gamma_{i}},
$$

where $\phi_{i} \equiv \theta-\underline{\theta}_{i}$. Note that $\phi_{i}$ represents a degree of investor $i$ 's ambiguity.

Proposition 1 Fix $M \in 2^{N} \backslash\{\emptyset\}$ with $m=|M|$. The following price function $p_{M}$ for $M$ is a rational expectations equilibrium for $M$ :

$$
p_{M}\left(\tilde{s}_{M}\right)=E_{\theta}\left[\tilde{v} \mid \tilde{s}_{M}\right]-\frac{\alpha}{\alpha+m \beta} \min _{M^{\prime} \subseteq M} \Phi\left(M^{\prime}\right),
$$

where

$$
E_{\theta}\left[\tilde{v} \mid \tilde{s}_{M}\right]=\frac{\alpha}{\alpha+m \beta} \theta+\frac{m \beta}{\alpha+m \beta} \frac{\sum_{i \in M} \tilde{s}_{i}}{m} .
$$

Let $M^{*}=\left\{i \in M: \phi_{i}<\min _{M^{\prime} \subseteq M} \Phi\left(M^{\prime}\right)\right\}$. Then, $d_{i}\left(\tilde{p} \mid \tilde{I}_{i}\right)>0$ for each $i \in M^{*}$ and $d_{i}\left(\tilde{p} \mid \tilde{I}_{i}\right)=0$ for each $i \in M \backslash M^{*}$, where $\tilde{I}_{i}=\left(\tilde{s}_{i}, \tilde{p}\right)$ and $\tilde{p}=p_{M}\left(\tilde{s}_{M}\right)$.

Proposition 2 For each $M \in 2^{N} \backslash\{\emptyset\}$, let $p_{M}$ be the rational expectations equilibrium for $M$ given in Proposition 1. Let $N^{*}=\left\{i \in N: \phi_{i}<\min _{N^{\prime} \subseteq N} \Phi\left(N^{\prime}\right)\right\}$. Then, $p_{N^{*}}$ is the unique rational expectations equilibrium with endogenous participation given $\left\{p_{M}\right\}_{M \in 2^{N} \backslash\{\emptyset\}}$.

The following lemma characterizes $M^{*}$ and $N^{*}$.

\footnotetext{
${ }^{20}$ We do not consider a continuum of investors to avoid a measurability issue of $\Theta_{i}$ 's and simplify our analysis.
} 
Lemma 1 For each $M \in 2^{N} \backslash\{\emptyset\}, M^{*}=\left\{i \in M: \phi_{i}<\min _{M^{\prime} \subseteq M} \Phi\left(M^{\prime}\right)\right\}$ if and only if $M^{*}$ is a minimal set contained in $\arg \min _{M^{\prime} \subseteq M} \Phi\left(M^{\prime}\right)$. Also, $M^{*}=\left\{i \in M: \phi_{i}<\right.$ $\left.\min _{M^{\prime} \subseteq M} \Phi\left(M^{\prime}\right)\right\}$ if and only if $M^{*}=\left\{i \in M: \phi_{i}<\Phi\left(M^{*}\right)\right\}$.

Proofs of the above results are relegated to the appendix.

Remark 1 If $\beta=0$, then $p_{N^{*}}$ is the competitive equilibrium studied by Cao et al. (2005) and Easley and O'Hara (2009). If $\Theta_{i}=\{\theta\}$ for each $i \in N$, then $\phi_{i}=0$ and $\Phi(M)=z /\left(\alpha \sum_{i \in M} \gamma_{i}\right)$, which implies that $N^{*}=N$. In this case, $p_{N^{*}}$ is the rational expectations equilibrium obtained by Grossman (1976).

Remark 2 Note that investor $i$ does not update $\Theta_{i}$ after observing the prices. This is because we assume the full Bayesian updating of maxmin expected utility preferences. For justification of the full Bayesian updating, see papers in footnote 14. Concerning this issue, we also assume that investor $i$ does not know $\Theta_{j}$ with $j \neq i$, by which we exclude the contradictory case where investor $i$ does not know $\theta$ (i.e. $\Theta_{i} \neq\{\theta\}$ ) but he knows $\Theta_{j}=\{\theta\}$. This assumption is necessary in most models with heterogeneous ambiguity profiles. For example, in the models of Easley and O'Hara (2009) and Condie and Ganguli (2008), there are two groups of investors: investors in one group know the true prior and investors in the other group do not, and this difference does not change by observing the prices, which implies that the latter investors cannot know what the former investors know.

Remark 3 If investor $j \notin N^{*}$ receives a private signal $\tilde{s}_{j}$, then $\tilde{p}=p_{N^{*}}\left(\tilde{s}_{N^{*}}\right)$ is not a market clearing price. In this case, investor $j$ 's information is $\tilde{I}_{j}=\left(\tilde{s}_{j}, \tilde{p}\right)$, where $\tilde{p}$ does not reflect $\tilde{s}_{j}$. If $\tilde{s}_{j}$ conveys very good news compared to $\tilde{p}$, then investor $j$ wants to purchase the risky asset. This event occurs with a positive probability, when $\tilde{p}$ is not a market clearing price. If investor $j \notin N^{*}$ receiving very good news tries to purchase the risky asset, then the price rises reflecting his private signal, but he does not want to purchase the risky asset at the higher market clearing price; that is, this market clearing price reflects a private signal of an investor who does not trade the risky asset at all. Therefore, the condition that a non-participating investor does not receive a private signal is indispensable for the existence of a market clearing price that depends solely upon private signals of investors trading non-zero units of the risky asset.

Remark 4 When $\tilde{s}_{N^{*}}$ is available, $\sum_{i \in N^{*}} \tilde{s}_{i}$ is sufficient for $\tilde{v}$. Since $\sum_{i \in N^{*}} \tilde{s}_{i}$ can be written as a linear function of $\tilde{p}=p_{N^{*}}\left(\tilde{s}_{N^{*}}\right), \tilde{p}$ is also sufficient for $\tilde{v}$. Thus, $p_{N^{*}}$ is fully revealing or informationally efficient in the sense that $E_{\theta}\left[\tilde{v} \mid \tilde{I}_{i}\right]=E_{\theta}\left[\tilde{v} \mid \tilde{s}_{N^{*}}\right]$ for each 
$i \in N^{*}$ where $\tilde{I}_{i}=\left(\tilde{s}_{i}, \tilde{p}\right)$. It is well known that informational efficiency raises the conceptual problem of the Grossman-Stiglitz paradox (Grossman and Stiglitz, 1980). The notion of noisy rational expectations equilibrium has been developed to address this problem. But if we adopt a noisy rational expectations equilibrium in this paper, our analysis of the premiums would be far more complicated due to the following reason. If the supply of the risky asset is noisy, then each private signal contains information not reflected in a price. Thus, an investor trades the risky asset if his private signal conveys very good news or very bad news compared to the price, and he does not trade it otherwise. This implies that a set of participating investors may depend upon the realization of private signals. Furthermore, by the same reason as that discussed in Remark 3, there may be no market clearing price that depends solely upon private signals of investors trading non-zero units of the risky asset. Thus, it is not straightforward to extend our model to the model with a noisy supply of the risky asset, where a more elaborate equilibrium concept might be necessary. In order to simplify our analysis of the premiums, we sidestep the Grossman-Stiglitz paradox. Ozsoylev and Werner (2006) consider a noisy rational expectations equilibrium with an ambiguity-averse investor and avoid the above kind of difficulties by assuming that an ambiguity-averse investor does not have a private signal. We also mention recent papers by Muendler (2007) and Krebs (2007) who consider models which reconcile the Grossman-Stiglitz paradox and informationally efficient rational expectations equilibria.

Remark 5 A rational expectations equilibrium is not necessarily unique in multiple priors models. In fact, Condie and Ganguli (2008) consider multiple priors models possessing both a fully revealing rational expectations equilibrium and a partially revealing one. This is in clear contrast to the single prior model of Grossman (1976) because the fully revealing rational expectations equilibrium is the unique rational expectations equilibrium as shown by DeMarzo and Skiadas (1998). Using the idea of Condie and Ganguli (2008), we could construct a partially revealing rational expectations equilibrium in our model. However, a partially revealing rational expectations equilibrium is not unique, and it is not linear in private signals, which would make the analysis complicated. In order to make our analysis tractable, we restrict attention to a linear and fully revealing rational expectations equilibrium.

Remark 6 The equilibrium price $p_{N^{*}}$ is written in terms of $\underline{\theta}_{i}$ 's. But it is not necessarily the same as a rational expectations equilibrium of a model in which investor $i$ has a single prior $N\left(\underline{\theta}_{i}, 1 / \alpha\right)$ for each $i \in N$, unless $\underline{\theta}_{i}=\underline{\theta}_{j}$ for all $i, j \in N$. In this single prior model, all investors trade non-zero units of the risky asset (generically), and some investors 
may sell the risky asset short. In fact, it can be verified that the rational expectations equilibrium of the single prior model is

$$
p\left(\tilde{s}_{N}\right) \equiv E_{\theta}\left[\tilde{v} \mid \tilde{s}_{N}\right]-\frac{\alpha}{\alpha+n \beta} \Phi(N),
$$

and investor $i \notin N^{*}$ sells the risky asset short. Note that $p\left(\tilde{s}_{N}\right) \leq p_{N}\left(\tilde{s}_{N}\right)$, which can be explained by the fact that investor $i \notin N^{*}$ trades no risky asset in our multiple priors model. As is well known, if investors have different single priors, then they have an incentive for speculation both in the ex ante stage and in the interim stage (Aumann, 1976; Milgrom and Stokey, 1982). This is the reason why there is a short sale in the above single prior model. In our multiple priors model, on the other hand, investor $i$ has a set of priors $\left\{N\left(\theta^{\prime}, 1 / \alpha\right)\right\}_{\theta^{\prime} \in \Theta_{i}}$ for each $i \in N$ with $\bigcap_{i \in N} \Theta_{i} \neq \emptyset$; that is, investors may have different sets of priors but there exists at least one common prior. If this is the case, investors have no incentive for speculation both in the ex ante stage (Billot et al., 2000; Rigotti et al., 2008) and in the interim stage (Kajii and Ui, 2009). This is the reason why there is no short sale in our multiple priors model. The assumption $\bigcap_{i \in N} \Theta_{i} \neq \emptyset$ is used in the proofs of the above propositions.

\section{Comparative statics under limited participation}

Let $p_{N^{*}}$ be the rational expectation equilibrium with endogenous participation given in Proposition 2. We define $E_{\theta}\left[\tilde{v} \mid \tilde{s}_{N^{*}}\right]-p_{N^{*}}\left(\tilde{s}_{N^{*}}\right)$ to be the equity premium in our model, and investigate comparative statics of the equity premium with respect to $\alpha, \beta$, and $\phi \equiv\left(\phi_{i}\right)_{i \in N}$, which are parameters of investors' knowledge or information. Recall that $\alpha$ is the precision of the stock return $\tilde{v}, \beta$ is the conditional precision of a private signal $\tilde{s}_{i}$, and $\phi_{i}=\theta-\underline{\theta}_{i}$ represents investor $i$ 's ambiguity. In the following, we write $\Phi(M \mid \alpha, \phi)$ for $\Phi(M)$ given by (1), which depends upon $\alpha$ and $\phi$ but not upon $\beta$. Let $N^{*}(\alpha, \phi)=$ $\left\{i \in N: \phi_{i}<\min _{N^{\prime} \subseteq N} \Phi\left(N^{\prime} \mid \alpha, \phi\right)\right\}$, which is the set of participating investors by Proposition 2. We write $n^{*}(\alpha, \phi)=\left|N^{*}(\alpha, \phi)\right|$ and $\Phi^{*}(\alpha, \phi)=\min _{N^{\prime} \subseteq N} \Phi\left(N^{\prime} \mid \alpha, \phi\right)=$ $\Phi\left(N^{*}(\alpha, \phi) \mid \alpha, \phi\right)$, where the last equality holds by Lemma 1 . Then, by Proposition 1 and Proposition 2, the equity premium is

$$
E P(\alpha, \beta, \phi)=E_{\theta}\left[\tilde{v} \mid \tilde{s}_{N^{*}}\right]-p_{N^{*}}\left(\tilde{s}_{N^{*}}\right)=\frac{\alpha \Phi^{*}(\alpha, \phi)}{\alpha+n^{*}(\alpha, \phi) \beta}=R P(\alpha, \beta, \phi)+A P(\alpha, \beta, \phi),
$$


where

$$
\begin{aligned}
& R P(\alpha, \beta, \phi)=\frac{z}{\left(\alpha+n^{*}(\alpha, \phi) \beta\right) \sum_{i \in N^{*}(\alpha, \phi)} \gamma_{i}}, \\
& A P(\alpha, \beta, \phi)=\frac{\alpha \sum_{i \in N^{*}(\alpha, \phi)} \gamma_{i} \phi_{i}}{\left(\alpha+n^{*}(\alpha, \phi) \beta\right) \sum_{i \in N^{*}(\alpha, \phi)} \gamma_{i}} .
\end{aligned}
$$

We call $R P(\alpha, \beta, \phi)$ the risk premium and call $A P(\alpha, \beta, \phi)$ the ambiguity premium. The risk premium is equal to the equity premium if $\Theta_{i}=\{\theta\}$ for all $i \in N$. The ambiguity premium comes from investors' ambiguity aversion and depends upon the weighted average of investors' ambiguity. Note that $E P(\alpha, \beta, \phi)$ is decreasing in $\beta$ and that $N^{*}(\alpha, \phi)$ is independent of $\beta$. Thus, in the remainder of this section, we restrict attention to a change in $\alpha$ or $\phi$ which induces limited market participation.

We consider pairs of parameters $(\alpha, \phi),\left(\alpha^{\prime}, \phi\right)$, and $\left(\alpha, \phi^{\prime}\right)$ such that $N^{*}(\alpha, \phi)=N$, $N^{*}\left(\alpha^{\prime}, \phi\right) \subsetneq N$, and $N^{*}\left(\alpha, \phi^{\prime}\right) \subsetneq N$, and study the signs of $E P\left(\alpha^{\prime}, \beta, \phi\right)-E P(\alpha, \beta, \phi)$ and $E P\left(\alpha, \beta, \phi^{\prime}\right)-E P(\alpha, \beta, \phi)$. By Lemma $1, N^{*}(\alpha, \phi)=N$ if and only if $\phi_{i}<\Phi(N \mid \alpha, \phi)$ for all $i \in N$, or equivalently,

$$
\alpha\left(\max _{j} \phi_{j}-\frac{\sum_{i \in N} \gamma_{i} \phi_{i}}{\sum_{i \in N} \gamma_{i}}\right)<\frac{z}{\sum_{i \in N} \gamma_{i}} .
$$

This immediately implies the following lemma.

Lemma 2 For $\alpha$ and $\phi$, assume that $N^{*}(\alpha, \phi)=N$. If $N^{*}\left(\alpha^{\prime}, \phi\right) \subsetneq N$, then $\alpha<\alpha^{\prime}$. If $N^{*}\left(\alpha, \phi^{\prime}\right) \subsetneq N$, then $\max _{j} \phi_{j}^{\prime}-\sum_{i \in N} \gamma_{i} \phi_{i}^{\prime} /\left(\sum_{i \in N} \gamma_{i}\right)>\max _{j} \phi_{j}-\sum_{i \in N} \gamma_{i} \phi_{i} /\left(\sum_{i \in N} \gamma_{i}\right)$.

This lemma says the following. When limited market participation arises by a change in the precision of the stock return, the precision must increase. When limited market participation arises by a change in investors' ambiguity, the largest deviation of investors' ambiguity must increase.

In the remainder of this section, we assume that $\alpha>0$ and $\beta \geq 0$. We allow $\beta=0$ in order to consider the case without private signals. In the appendix, we consider the equity premium under the standard rational expectations equilibrium and examine the robustness of the results in the subsequent subsections. ${ }^{21}$

\subsection{Limited market participation induced by a change in ambiguity}

We first consider limited market participation induced by a change in investors' ambiguity. Note that, for $N^{\prime} \subsetneq N$ with $n^{\prime}=\left|N^{\prime}\right|$,

${ }^{21}$ I thank the referee for suggesting this.

$$
\frac{z}{(\alpha+n \beta) \sum_{i \in N} \gamma_{i}}<\frac{z}{\left(\alpha+n^{\prime} \beta\right) \sum_{i \in N^{\prime}} \gamma_{i}} \text {. }
$$


This implies that the risk premium increases when limited market participation arises. On the other hand, the ambiguity premium may decrease as the following examples demonstrate. The first two examples are simplified versions of the model of Easley and O'Hara (2009) and that of Cao et al. (2005) respectively.

Example 1 Assume that $\alpha=1, \beta=0$, and $\gamma_{i}=1$ for all $i \in N$. Let $\phi$ and $\phi^{\prime}$ be such that $\phi_{i}, \phi_{i}^{\prime} \in\{0, r\}$ for all $i \in N$, where $r>0$. Assume the following: $\phi_{i}=0$ for $i \in\{1, \ldots, m\} ; \phi_{i}=r$ for $i \in\{m+1, \ldots, n\} ; \phi_{i}^{\prime}=0$ for $i \in\left\{1, \ldots, m^{\prime}\right\} ; \phi_{i}^{\prime}=r$ for $i \in\left\{m^{\prime}+1, \ldots, n\right\} ; 1<m<z / r<m^{\prime}<n$. Then, for $j \geq m+1$ and $j^{\prime} \geq m^{\prime}+1$,

$$
\phi_{j}-\frac{\sum_{i \in N} \gamma_{i} \phi_{i}}{\sum_{i \in N} \gamma_{i}}=\frac{m r}{n}<\frac{z}{n}=\frac{z}{\sum_{i \in N} \gamma_{i}}<\frac{m^{\prime} r}{n}=\phi_{j^{\prime}}^{\prime}-\frac{\sum_{i \in N} \gamma_{i} \phi_{i}^{\prime}}{\sum_{i \in N} \gamma_{i}} .
$$

Thus, $N^{*}\left(1, \phi^{\prime}\right)=\left\{1, \ldots, m^{\prime}\right\} \subsetneq N=N^{*}(1, \phi)$, and

$$
\begin{aligned}
R P\left(1,0, \phi^{\prime}\right)-R P(1,0, \phi) & =\frac{z}{m^{\prime}}-\frac{z}{n}>0, \\
A P\left(1,0, \phi^{\prime}\right)-A P(1,0, \phi) & =0-\frac{(n-m) r}{n}<0, \\
E P\left(1,0, \phi^{\prime}\right)-E P(1,0, \phi) & =\frac{z}{m^{\prime}}-\frac{z}{n}-\frac{(n-m) r}{n} \\
& <\frac{z}{m^{\prime}}-\frac{z}{n}-\frac{\left(n-m^{\prime}\right) r}{n}=\frac{n-m^{\prime}}{n}\left(\frac{z}{m^{\prime}}-r\right)<0 .
\end{aligned}
$$

Therefore, by the occurrence of limited market participation, the risk premium increases, the ambiguity premium decreases, and the equity premium decreases. This result is obtained by Easley and O'Hara (2009) for a continuum of investors. Note that $\sum_{i \in N} \gamma_{i} \phi_{i}=(n-m) r>\left(n-m^{\prime}\right) r=\sum_{i \in N} \gamma_{i} \phi_{i}^{\prime}$, which will turn out to be essential for this result.

Example 2 Assume that $\alpha=1, \beta=0$, and $\gamma_{i}=1$ for all $i \in N$. Let $\phi$ and $\phi^{\prime}$ be such that $\phi_{i} \in\{r-d, r+d\}$ and $\phi_{i}^{\prime} \in\left\{r-d^{\prime}, r+d^{\prime}\right\}$ for all $i \in N$, where $r>d^{\prime}>d>0$. Assume the following: $\phi_{i}=r-d$ and $\phi_{i}^{\prime}=r-d^{\prime}$ for $i \in\{1, \ldots, m\} ; \phi_{i}=r+d$ and $\phi_{i}^{\prime}=r+d^{\prime}$ for $i \in\{m+1, \ldots, n\} ; n=2 m ; d<z / n<d^{\prime}$. Then, for $j \geq m+1$,

$$
\phi_{j}-\frac{\sum_{i \in N} \gamma_{i} \phi_{i}}{\sum_{i \in N} \gamma_{i}}=d<\frac{z}{n}=\frac{z}{\sum_{i \in N} \gamma_{i}}<d^{\prime}=\phi_{j}^{\prime}-\frac{\sum_{i \in N} \gamma_{i} \phi_{i}^{\prime}}{\sum_{i \in N} \gamma_{i}} .
$$

Thus, $N^{*}\left(1, \phi^{\prime}\right)=\{1, \ldots, m\} \subsetneq N=N^{*}(1, \phi)$, and

$$
\begin{aligned}
& R P\left(1,0, \phi^{\prime}\right)-R P(1,0, \phi)=\frac{z}{m}-\frac{z}{2 m}>0, \\
& A P\left(1,0, \phi^{\prime}\right)-A P(1,0, \phi)=r-d^{\prime}-r<0, \\
& E P\left(1,0, \phi^{\prime}\right)-E P(1,0, \phi)=\frac{z}{m}+\left(r-d^{\prime}\right)-\frac{z}{2 m}-r=\frac{z}{n}-d^{\prime}<0 .
\end{aligned}
$$


Therefore, by the occurrence of limited market participation, the risk premium increases, the ambiguity premium decreases, and the equity premium decreases. This result is obtained by Cao et al. (2005) for a continuum of investors and uniformly distributed $\phi_{i}$ with a fixed mean $r$. Note that $\sum_{i \in N} \gamma_{i} \phi_{i}=n r=\sum_{i \in N} \gamma_{i} \phi_{i}^{\prime}$, which will turn out to be essential for this result.

Example 3 Assume that $\alpha=1, \beta=0$, and $\gamma_{i}=1$ for all $i \in N$. Let $\phi$ and $\phi^{\prime}$ be such that $\phi_{i} \in\{r, r+d\}$ and $\phi_{i}^{\prime} \in\left\{r, r+d^{\prime}\right\}$ for all $i \in N$, where $r \geq 0$ and $d^{\prime}>d>0$. Assume the following: $\phi_{i}=\phi_{i}^{\prime}=r$ for $i \in\{1, \ldots, m\} ; \phi_{i}=r+d$ and $\phi_{i}^{\prime}=r+d^{\prime}$ for $i \in\{m+1, \ldots, n\} ; 1<m<n ; d<z / m<d^{\prime}$. Then, for $j \geq m+1$,

$$
\phi_{j}-\frac{\sum_{i \in N} \gamma_{i} \phi_{i}}{\sum_{i \in N} \gamma_{i}}=\frac{m d}{n}<\frac{z}{n}=\frac{z}{\sum_{i \in N} \gamma_{i}}<\frac{m d^{\prime}}{n}=\phi_{j}^{\prime}-\frac{\sum_{i \in N} \gamma_{i} \phi_{i}^{\prime}}{\sum_{i \in N} \gamma_{i}} .
$$

Thus, $N^{*}\left(1, \phi^{\prime}\right)=\{1, \ldots, m\} \subsetneq N=N^{*}(1, \phi)$, and

$$
\begin{aligned}
& R P\left(1,0, \phi^{\prime}\right)-R P(1,0, \phi)=\frac{z}{m}-\frac{z}{n}>0, \\
& A P\left(1,0, \phi^{\prime}\right)-A P(1,0, \phi)=r-r-\frac{n-m}{n} d<0, \\
& E P\left(1,0, \phi^{\prime}\right)-E P(1,0, \phi)=\frac{z}{m}+r-\frac{z}{n}-r-\frac{n-m}{n} d=\frac{n-m}{n}\left(\frac{z}{m}-d\right)>0 .
\end{aligned}
$$

Therefore, by the occurrence of limited market participation, the risk premium increases, the ambiguity premium decreases, and the equity premium increases. Note that $\sum_{i \in N^{*}\left(1, \phi^{\prime}\right)} \gamma_{i} \phi_{i}=m r=\sum_{i \in N^{*}\left(1, \phi^{\prime}\right)} \gamma_{i} \phi_{i}^{\prime}$, which will turn out to be essential for this result.

We study the sign of $E P\left(\alpha, \beta, \phi^{\prime}\right)-E P(\alpha, \beta, \phi)$ in terms of

$$
\delta\left(\phi, \phi^{\prime}\right) \equiv \frac{\sum_{i \in N^{*}\left(\alpha, \phi^{\prime}\right)} \gamma_{i} \phi_{i}^{\prime}}{\sum_{i \in N^{*}\left(\alpha, \phi^{\prime}\right)} \gamma_{i}}-\frac{\sum_{i \in N^{*}(\alpha, \phi)} \gamma_{i} \phi_{i}}{\sum_{i \in N^{*}(\alpha, \phi)} \gamma_{i}},
$$

which is the difference between the weighted average of participating investors' ambiguity under limited market participation and that under full market participation.

Proposition 3 Let $\alpha, \phi, \phi^{\prime}$ be such that $N^{*}\left(\alpha, \phi^{\prime}\right)=N^{\prime} \subsetneq N=N^{*}(\alpha, \phi)$ with $n^{\prime}=\left|N^{\prime}\right|$. Assume that $\operatorname{EP}(\alpha, \beta, \phi)>0$. Define

$$
\begin{aligned}
A & \equiv \frac{\alpha}{n} \cdot \frac{\Delta^{*}-\delta\left(\phi, \phi^{\prime}\right)}{\delta\left(\phi, \phi^{\prime}\right)-\Delta_{*}}, \\
\Delta_{*} & \equiv-\frac{z \sum_{i \in N \backslash N^{\prime}} \gamma_{i}}{\alpha \sum_{i \in N^{\prime}} \gamma_{i} \sum_{i \in N} \gamma_{i}}-\frac{\left(n-n^{\prime}\right) \Phi^{*}(\alpha, \phi)}{n}, \\
\Delta^{*} & \equiv-\frac{z \sum_{i \in N \backslash N^{\prime}} \gamma_{i}}{\alpha \sum_{i \in N^{\prime}} \gamma_{i} \sum_{i \in N} \gamma_{i}} .
\end{aligned}
$$


If $\delta\left(\phi, \phi^{\prime}\right)>\Delta^{*}$, or if $\Delta_{*}<\delta\left(\phi, \phi^{\prime}\right) \leq \Delta^{*}$ and $\beta>A$, then $\operatorname{EP}\left(\alpha, \beta, \phi^{\prime}\right)>\operatorname{EP}(\alpha, \beta, \phi)$. If $\delta\left(\phi, \phi^{\prime}\right) \leq \Delta_{*}$, or if $\Delta_{*}<\delta\left(\phi, \phi^{\prime}\right) \leq \Delta^{*}$ and $\beta<A$, then $\operatorname{EP}\left(\alpha, \beta, \phi^{\prime}\right)<\operatorname{EP}(\alpha, \beta, \phi)$. If $\Delta_{*}<\delta\left(\phi, \phi^{\prime}\right) \leq \Delta^{*}$ and $\beta=A$, then $E P\left(\alpha, \beta, \phi^{\prime}\right)=E P(\alpha, \beta, \phi)$.

Proof. Since $\Phi^{*}(\alpha, \phi)=(\alpha+n \beta) E P(\alpha, \beta, \phi) / \alpha>0, \Delta^{*}>\Delta_{*}$ holds. By calculation, we have

$$
\begin{aligned}
E P & \left(\alpha, \beta, \phi^{\prime}\right)-E P(\alpha, \beta, \phi) \\
& =\frac{\alpha}{(\alpha+n \beta)\left(\alpha+n^{\prime} \beta\right)}\left(\beta\left(n \Phi^{*}\left(\alpha, \phi^{\prime}\right)-n^{\prime} \Phi^{*}(\alpha, \phi)\right)-\alpha\left(\Phi^{*}(\alpha, \phi)-\Phi^{*}\left(\alpha, \phi^{\prime}\right)\right)\right) \\
& =\frac{n \alpha}{(\alpha+n \beta)\left(\alpha+n^{\prime} \beta\right)}\left(\beta\left(\delta\left(\phi, \phi^{\prime}\right)-\Delta_{*}\right)-\frac{\alpha}{n}\left(\Delta^{*}-\delta\left(\phi, \phi^{\prime}\right)\right)\right) .
\end{aligned}
$$

Since $\Delta^{*}>\Delta_{*}$, if $\delta\left(\phi, \phi^{\prime}\right)>\Delta^{*}$, then $E P\left(\alpha, \beta, \phi^{\prime}\right)-E P(\alpha, \beta, \phi)>0$, and if $\delta\left(\phi, \phi^{\prime}\right) \leq$ $\Delta_{*}$, then $E P\left(\alpha, \beta, \phi^{\prime}\right)-E P(\alpha, \beta, \phi)<0$. Suppose that $\Delta_{*}<\delta\left(\phi, \phi^{\prime}\right) \leq \Delta^{*}$. Then, $A \geq 0$ and

$$
E P\left(\alpha, \beta, \phi^{\prime}\right)-E P(\alpha, \beta, \phi)=\frac{n \alpha\left(\delta\left(\phi, \phi^{\prime}\right)-\Delta_{*}\right)}{(\alpha+n \beta)\left(\alpha+n^{\prime} \beta\right)}(\beta-A)
$$

Thus, the sign of $\beta-A$ and that of $E P\left(\alpha, \beta, \phi^{\prime}\right)-E P(\alpha, \beta, \phi)$ coincide.

This proposition says that, when limited market participation arises by a change in $\phi$, the equity premium increases if and only if either $\delta\left(\phi, \phi^{\prime}\right)$ is larger than $\Delta^{*}$, or it is in the interval $\left(\Delta_{*}, \Delta^{*}\right]$ and $\beta$ is larger than $A$. In the latter case, the precision of private signals plays an important role because of the following effect: if the precision is very large, information revealed by private signals diminishes to a large extent by the exit of informed investors, and the increased conditional variance of the stock return enlarges the equity premium.

For the case without private signals, we have the following corollary.

Corollary 4 Let $\alpha, \phi, \phi^{\prime}$ be such that $N^{*}\left(\alpha, \phi^{\prime}\right)=N^{\prime} \subsetneq N=N^{*}(\alpha, \phi)$ with $n^{\prime}=\left|N^{\prime}\right|$. If $\delta\left(\phi, \phi^{\prime}\right)>\Delta^{*}$, then $\operatorname{EP}\left(\alpha, 0, \phi^{\prime}\right)>\operatorname{EP}(\alpha, 0, \phi)$. If $\delta\left(\phi, \phi^{\prime}\right)<\Delta^{*}$, then $\operatorname{EP}\left(\alpha, 0, \phi^{\prime}\right)<$ $E P(\alpha, 0, \phi)$. If $\delta\left(\phi, \phi^{\prime}\right)=\Delta^{*}$, then $E P\left(\alpha, 0, \phi^{\prime}\right)=E P(\alpha, 0, \phi)$.

Proof. If $\beta=0$, then (4) is reduced to

$$
E P\left(\alpha, \beta, \phi^{\prime}\right)-E P(\alpha, \beta, \phi)=\delta\left(\phi, \phi^{\prime}\right)-\Delta^{*}
$$

This implies the corollary.

This corollary says that, even without private signals, if $\delta\left(\phi, \phi^{\prime}\right)>\Delta^{*}$, then the equity premium increases when limited market participation arises. By this corollary, 
we can understand the above examples without private signals. But for this purpose, the next two corollaries are more useful. The first corollary restricts attention to investors in $N^{*}\left(\alpha, \phi^{\prime}\right) \subsetneq N$, and shows that if the weighted sum of these investors' ambiguity does not decrease when limited market participation arises, then the equity premium increases.

Corollary 5 Let $\alpha, \phi, \phi^{\prime}$ be such that $N^{*}\left(\alpha, \phi^{\prime}\right)=N^{\prime} \subsetneq N=N^{*}(\alpha, \phi)$. Assume that $E P(\alpha, \beta, \phi)>0$. If $\sum_{i \in N^{\prime}} \gamma_{i} \phi_{i}^{\prime} \geq \sum_{i \in N^{\prime}} \gamma_{i} \phi_{i}$, then $\operatorname{EP}\left(\alpha, \beta, \phi^{\prime}\right)>E P(\alpha, \beta, \phi)$.

Proof. Since $\sum_{i \in N^{\prime}} \gamma_{i} \phi_{i}^{\prime} \geq \sum_{i \in N^{\prime}} \gamma_{i} \phi_{i}, \Phi\left(N^{\prime} \mid \alpha, \phi^{\prime}\right) \geq \Phi\left(N^{\prime} \mid \alpha, \phi\right)$. Since $N$ is a minimal set contained in $\arg \min _{M \subseteq N} \Phi(M \mid \alpha, \phi)$ by Lemma $1, \Phi\left(N^{\prime} \mid \alpha, \phi\right)>\Phi(N \mid \alpha, \phi)$. Thus, $\Phi^{*}\left(\alpha, \phi^{\prime}\right)=\Phi\left(N^{\prime} \mid \alpha, \phi^{\prime}\right) \geq \Phi\left(N^{\prime} \mid \alpha, \phi\right)>\Phi(N \mid \alpha, \phi)=\Phi^{*}(\alpha, \phi)$, and

$$
\delta\left(\phi, \phi^{\prime}\right)=\Phi^{*}\left(\alpha, \phi^{\prime}\right)-\Phi^{*}(\alpha, \phi)-\frac{z \sum_{i \in N \backslash N^{\prime}} \gamma_{i}}{\alpha \sum_{i \in N^{\prime}} \gamma_{i} \sum_{i \in N} \gamma_{i}}>-\frac{z \sum_{i \in N \backslash N^{\prime}} \gamma_{i}}{\alpha \sum_{i \in N^{\prime}} \gamma_{i} \sum_{i \in N} \gamma_{i}}=\Delta^{*} .
$$

Therefore, $E P\left(\alpha, \beta, \phi^{\prime}\right)>E P(\alpha, \beta, \phi)$ by Proposition 3 .

In Example 3, it holds that $\sum_{i \in N^{\prime}} \gamma_{i} \phi_{i}^{\prime}=\sum_{i \in N^{\prime}} \gamma_{i} \phi_{i}$, by which $E P\left(\alpha, 0, \phi^{\prime}\right)>$ $E P(\alpha, 0, \phi)$ follows.

The intuition behind Corollary 5 can be illustrated as follows. For the sake of simplicity, imagine that there is no private signal $(\beta=0)$ and that preferences of investors in $N^{\prime}$ stay the same under both $\phi$ and $\phi^{\prime}\left(\phi_{i}=\phi_{i}^{\prime}\right.$ for all $\left.i \in N^{\prime}\right)$. Consider a price at which all investors want to purchase the risky asset under $\phi$. At this price, the total demand of investors in $N$ under $\phi$ is greater than that of investors in $N^{\prime}$ under $\phi^{\prime}$ since $N^{\prime} \subsetneq N$ and $\phi_{i}=\phi_{i}^{\prime}$ for all $i \in N^{\prime}$. Thus, the equilibrium price under $\phi$, where $N$ is the set of participating investors, must be greater than that under $\phi^{\prime}$, where $N^{\prime}$ is the set of participating investors, since the supply is fixed. In other words, the equity premium under $\phi$ is less than that under $\phi^{\prime}$. We can generalize this observation to explain the above corollary noting that the equity premium depends upon $\phi$ through $\sum_{i \in N^{*}(\alpha, \phi)} \gamma_{i} \phi_{i}$ and it is increasing in $\sum_{i \in N^{*}(\alpha, \phi)} \gamma_{i} \phi_{i}$.

The second corollary shows that if the weighted sum of all investors' ambiguity does not increase when limited market participation arises and $\beta$ is small enough, then the equity premium decreases.

Corollary 6 Let $\alpha, \phi, \phi^{\prime}$ be such that $N^{*}\left(\alpha, \phi^{\prime}\right)=N^{\prime} \subsetneq N=N^{*}(\alpha, \phi)$. Assume that $E P(\alpha, \beta, \phi)>0$. If $\sum_{i \in N} \gamma_{i} \phi_{i}^{\prime}<\sum_{i \in N} \gamma_{i} \phi_{i}$, or if $\sum_{i \in N} \gamma_{i} \phi_{i}^{\prime}=\sum_{i \in N} \gamma_{i} \phi_{i}$ and $\Phi^{*}\left(\alpha, \phi^{\prime}\right)<\Phi\left(N \mid \alpha, \phi^{\prime}\right)$, then there exists $\bar{\beta}>0$ such that $\operatorname{EP}\left(\alpha, \beta, \phi^{\prime}\right)<E P(\alpha, \beta, \phi)$ for all $\beta<\bar{\beta}$. 
Proof. If $\delta\left(\phi, \phi^{\prime}\right) \leq \Delta_{*}$, then $E P\left(\alpha, \beta, \phi^{\prime}\right)<E P(\alpha, \beta, \phi)$ for all $\beta \geq 0$ by Proposition 3 . Suppose that $\delta\left(\phi, \phi^{\prime}\right)>\Delta_{*}$. If $\Phi^{*}\left(\alpha, \phi^{\prime}\right)<\Phi^{*}(\alpha, \phi)$, then

$$
\delta\left(\phi, \phi^{\prime}\right)=\Phi^{*}\left(\alpha, \phi^{\prime}\right)-\Phi^{*}(\alpha, \phi)-\frac{z \sum_{i \in N \backslash N^{\prime}} \gamma_{i}}{\alpha \sum_{i \in N^{\prime}} \gamma_{i} \sum_{i \in N} \gamma_{i}}<-\frac{z \sum_{i \in N \backslash N^{\prime}} \gamma_{i}}{\alpha \sum_{i \in N^{\prime}} \gamma_{i} \sum_{i \in N} \gamma_{i}}=\Delta^{*}
$$

which implies that $A>0$ and $E P\left(\alpha, \beta, \phi^{\prime}\right)<E P(\alpha, \beta, \phi)$ for all $\beta<A$ by Proposition 3. Thus, it is enough to show that $\Phi^{*}\left(\alpha, \phi^{\prime}\right)<\Phi^{*}(\alpha, \phi)$. If $\sum_{i \in N} \gamma_{i} \phi_{i}^{\prime}<\sum_{i \in N} \gamma_{i} \phi_{i}$, then $\Phi^{*}(\alpha, \phi)=\Phi(N \mid \alpha, \phi)>\Phi\left(N \mid \alpha, \phi^{\prime}\right) \geq \min _{M \subseteq N} \Phi\left(M \mid \alpha, \phi^{\prime}\right)=\Phi^{*}\left(\alpha, \phi^{\prime}\right)$. If $\sum_{i \in N} \gamma_{i} \phi_{i}^{\prime}=$ $\sum_{i \in N} \gamma_{i} \phi_{i}$ and $\Phi^{*}\left(\alpha, \phi^{\prime}\right)<\Phi\left(N \mid \alpha, \phi^{\prime}\right)$, then $\Phi^{*}(\alpha, \phi)=\Phi(N \mid \alpha, \phi)=\Phi\left(N \mid \alpha, \phi^{\prime}\right)>$ $\Phi^{*}\left(\alpha, \phi^{\prime}\right)$.

Note that $\Phi^{*}\left(\alpha, \phi^{\prime}\right)=\min _{M \subseteq N} \Phi\left(M \mid \alpha, \phi^{\prime}\right) \leq \Phi\left(N \mid \alpha, \phi^{\prime}\right)$. Therefore, $\Phi^{*}\left(\alpha, \phi^{\prime}\right)<$ $\Phi\left(N \mid \alpha, \phi^{\prime}\right)$ holds generically.

In Example 1, it holds that $\sum_{i \in N} \gamma_{i} \phi_{i}^{\prime}<\sum_{i \in N} \gamma_{i} \phi_{i}$, and in Example 2, it holds that $\sum_{i \in N} \gamma_{i} \phi_{i}^{\prime}=\sum_{i \in N} \gamma_{i} \phi_{i}$ and $\Phi^{*}\left(\alpha, \phi^{\prime}\right)<\Phi\left(N \mid \alpha, \phi^{\prime}\right)$, by which $\operatorname{EP}\left(\alpha, \beta, \phi^{\prime}\right)<$ $\operatorname{EP}(\alpha, \beta, \phi)$ follows for sufficiently small $\beta$. But if $\beta$ is large enough, $E P\left(\alpha, \beta, \phi^{\prime}\right)>$ $E P(\alpha, \beta, \phi)$ can be true by Proposition 3. The following example illustrates this.

Example 4 Consider Example 2 but allow $\beta>0$. In addition to the assumption $d<$ $z / n<d^{\prime}$, we assume that $d^{\prime}<3 z /(2 n)+r / 2$. Since $N^{\prime}=N^{*}\left(1, \phi^{\prime}\right)=\{1, \ldots, n / 2\}$, we have $\delta\left(\phi, \phi^{\prime}\right)=-d^{\prime}, \Delta_{*}=-3 z /(2 n)-r / 2$, and $\Delta^{*}=-z / n$. Thus, $\Delta_{*}<\delta\left(\phi, \phi^{\prime}\right)<\Delta^{*}$. By Proposition $3, \operatorname{EP}\left(\alpha, \beta, \phi^{\prime}\right)>E P(\alpha, \beta, \phi)$ if and only if $\beta>A$, where

$$
A=\frac{\alpha}{n} \cdot \frac{\Delta^{*}-\delta\left(\phi, \phi^{\prime}\right)}{\delta\left(\phi, \phi^{\prime}\right)-\Delta_{*}}=\frac{1}{n} \cdot \frac{d^{\prime}-z / n}{3 z /(2 n)+r / 2-d^{\prime}}>0 .
$$

The intuition behind Corollary 6 can be illustrated as follows. For the sake of simplicity, imagine that there is no private signal $(\beta=0)$. Instead of the above multiple priors model, consider the single prior model in which investor $i$ has a single prior $N\left(\theta-\phi_{i}^{\prime}, 1 / \alpha\right)$ for each $i \in N$. As we mentioned in Remark 6 to Proposition 2, it can be verified that investors in $N^{\prime}$ purchase the risky asset and investors in $N \backslash N^{\prime}$ sell the risky asset short at the equilibrium price of the single prior model. Thus, at the equilibrium price, the total (net) demand of investors in $N$ is less than that of investors restricted to $N^{\prime}$. This implies that the equilibrium price of the single prior model when the set of investors is $N$ must be less than that when the set of investors is restricted to $N^{\prime}$. Let $p$ and $q$ denote the former price and the latter price respectively. Note that $p<q$. Now observe that $q$ is equal to the equilibrium price of the multiple priors model under $\phi^{\prime}$ because investor $i \in N^{\prime}$ purchases the risky asset using the prior $N\left(\theta-\phi_{i}^{\prime}, 1 / \alpha\right)$ both in the single prior model and in the multiple priors model. On the other hand, observe that 
$p$ is greater than the equilibrium price of the multiple priors model under $\phi$ because $\sum_{i \in N} \gamma_{i} \phi_{i}^{\prime} \leq \sum_{i \in N} \gamma_{i} \phi_{i}$ and

$$
p=E_{\theta}[\tilde{v}]-\left(\frac{z}{\alpha \sum_{i \in N} \gamma_{i}}+\frac{\sum_{i \in N} \gamma_{i} \phi_{i}^{\prime}}{\sum_{i \in N} \gamma_{i}}\right) \geq E_{\theta}[\tilde{v}]-\left(\frac{z}{\alpha \sum_{i \in N} \gamma_{i}}+\frac{\sum_{i \in N} \gamma_{i} \phi_{i}}{\sum_{i \in N} \gamma_{i}}\right),
$$

where the right hand side of the above inequality is the equilibrium price of the multiple priors model under $\phi$. Therefore, since $p<q$, the equilibrium price of the multiple priors model under $\phi$ is less than that under $\phi^{\prime}$. In other words, the equity premium under $\phi$ is greater than that under $\phi^{\prime}$. Note that, if the precision of private signals is very large, information revealed by private signals diminishes to a large extent by the exit of informed investors, and the equity premium under $\phi^{\prime}$ can be greater than that under $\phi$.

\subsection{Limited market participation induced by a change in the precision}

We next consider limited market participation induced by an increase in the precision of the stock return and study the sign of $E P\left(\alpha^{\prime}, \beta, \phi\right)-E P(\alpha, \beta, \phi)$ for $\alpha^{\prime}>\alpha$. Observe that $\partial R P(\alpha, \beta, \phi) / \partial \alpha<0$ and $\partial A P(\alpha, \beta, \phi) / \partial \alpha>0$ if $\alpha$ is an interior point of $\{x>0$ : $\left.N^{*}(x, \phi)=N\right\}, \beta>0$, and $\sum_{i \in N} \gamma_{i} \phi_{i}>0$. This implies that, as the precision of the stock return increases, the risk premium may decrease and the ambiguity premium may increase. The next proposition shows that the equity premium increases if and only if the precision of private signals is large enough, including the case with $N^{\prime}=N$.

Proposition 7 Let $\alpha, \alpha^{\prime}, \phi$ be such that $\alpha^{\prime}>\alpha$ and $N^{*}\left(\alpha^{\prime}, \phi\right)=N^{\prime} \subseteq N=N^{*}(\alpha, \phi)$ with $n^{\prime}=\left|N^{\prime}\right|$. Assume that $A P\left(\alpha^{\prime}, \beta, \phi\right)>0$. Define

$$
B \equiv \frac{\alpha \alpha^{\prime}\left(\Phi^{*}(\alpha, \phi)-\Phi^{*}\left(\alpha^{\prime}, \phi\right)\right)}{n \alpha^{\prime} \Phi^{*}\left(\alpha^{\prime}, \phi\right)-n^{\prime} \alpha \Phi^{*}(\alpha, \phi)} .
$$

If $\beta>B$, then $E P\left(\alpha^{\prime}, \beta, \phi\right)>E P(\alpha, \beta, \phi)$. If $\beta<B$, then $\operatorname{EP}\left(\alpha^{\prime}, \beta, \phi\right)<E P(\alpha, \beta, \phi)$. If $\beta=B$, then $E P\left(\alpha^{\prime}, \beta, \phi\right)=E P(\alpha, \beta, \phi)$. Furthermore, $B>0$.

Proof. Since $\Phi(N \mid \alpha, \phi)=z /\left(\alpha \sum_{i \in N} \gamma_{i}\right)+\sum_{i \in N} \gamma_{i} \phi_{i} /\left(\sum_{i \in N} \gamma_{i}\right)$ is strictly decreasing in $\alpha, \Phi^{*}(\alpha, \phi)=\Phi(N \mid \alpha, \phi)>\Phi\left(N \mid \alpha^{\prime}, \phi\right) \geq \min _{M \subseteq N} \Phi\left(M \mid \alpha^{\prime}, \phi\right)=\Phi^{*}\left(\alpha^{\prime}, \phi\right)$. Note that $\sum_{i \in N^{\prime}} \gamma_{i} \phi_{i} /\left(\sum_{i \in N^{\prime}} \gamma_{i}\right)=\left(\alpha^{\prime}+n^{\prime} \beta\right) A P\left(\alpha^{\prime}, \beta, \phi\right) / \alpha^{\prime}>0$. This implies that $\Phi\left(N^{\prime} \mid \alpha, \phi\right)>$ 0 and that $\alpha \Phi\left(N^{\prime} \mid \alpha, \phi\right)=z /\left(\sum_{i \in N^{\prime}} \gamma_{i}\right)+\alpha \sum_{i \in N^{\prime}} \gamma_{i} \phi_{i} /\left(\sum_{i \in N^{\prime}} \gamma_{i}\right)$ is strictly increasing in $\alpha$. Thus, $n^{\prime} \alpha \Phi^{*}(\alpha, \phi)=\min _{M \subseteq N} n^{\prime} \alpha \Phi(M \mid \alpha, \phi) \leq n^{\prime} \alpha \Phi\left(N^{\prime} \mid \alpha, \phi\right)<n^{\prime} \alpha^{\prime} \Phi\left(N^{\prime} \mid \alpha^{\prime}, \phi\right) \leq$ 
$n \alpha^{\prime} \Phi\left(N^{\prime} \mid \alpha^{\prime}, \phi\right)=n \alpha^{\prime} \Phi^{*}\left(\alpha^{\prime}, \phi\right)$. Therefore, $B>0$. By calculation, we have

$$
\begin{aligned}
E P\left(\alpha^{\prime}, \beta, \phi\right) & -E P(\alpha, \beta, \phi) \\
& =\frac{\beta\left(n \alpha^{\prime} \Phi^{*}\left(\alpha^{\prime}, \phi\right)-n^{\prime} \alpha \Phi^{*}(\alpha, \phi)\right)-\alpha \alpha^{\prime}\left(\Phi^{*}(\alpha, \phi)-\Phi^{*}\left(\alpha^{\prime}, \phi\right)\right)}{(\alpha+n \beta)\left(\alpha^{\prime}+n^{\prime} \beta\right)} \\
& =\frac{\left(n \alpha^{\prime} \Phi^{*}\left(\alpha^{\prime}, \phi\right)-n^{\prime} \alpha \Phi^{*}(\alpha, \phi)\right)(\beta-B)}{(\alpha+n \beta)\left(\alpha^{\prime}+n^{\prime} \beta\right)} .
\end{aligned}
$$

Since $n \alpha^{\prime} \Phi^{*}\left(\alpha^{\prime}, \phi\right)-n^{\prime} \alpha \Phi^{*}(\alpha, \phi)>0$, the sign of $\beta-B$ and that of $E P\left(\alpha^{\prime}, \beta, \phi\right)-$ $E P(\alpha, \beta, \phi)$ coincide.

This proposition implies that the larger precision of the stock return may result in the larger equity premium. On the other hand, if $\beta=0$, then $E P(\alpha, \beta, \phi)$ is decreasing in $\alpha$ by Proposition 7, and if $\phi_{i}=0$ for all $i \in N$, then $E P(\alpha, \beta, \phi)$ is decreasing in $\alpha$ since $E P(\alpha, \beta, 0)=R P(\alpha, \beta, 0)=z /\left((\alpha+n \beta) \sum_{i \in N} \gamma_{i}\right)$. Thus, without either ambiguity or private signals, the larger precision of the stock return results in the smaller equity premium.

The precision of private signals plays an important role partially because of the effect of private signals that appears in Proposition 3: information revealed by private signals diminishes by the exit of informed investors. But there is another effect of private signals because the equity premium can increase as the precision of the stock return increases even if no investors exit. To illustrate this effect, assume that $\phi_{i}=\phi_{j}>0$ for all $i, j \in N$, which implies that $N^{*}(\alpha, \phi)=N$ for all $\alpha>0$. By Proposition 7, $E P(\alpha, \beta, \phi)$ is strictly increasing in $\alpha$ if and only if $\beta>B=z /\left(n \sum_{i \in N} \gamma_{i} \phi_{i}\right)$. To reinterpret this, rewrite $E P(\alpha, \beta, \phi)$ as

$$
\begin{aligned}
E P(\alpha, \beta, \phi) & =\frac{\alpha}{\alpha+n \beta}\left(\frac{z}{\alpha \sum_{i \in N} \gamma_{i}}+\frac{\sum_{i \in N} \gamma_{i} \phi_{i}}{\sum_{i \in N} \gamma_{i}}\right) \\
& =\frac{n \beta}{\alpha+n \beta} \cdot \frac{z}{n \beta \sum_{i \in N} \gamma_{i}}+\left(1-\frac{n \beta}{\alpha+n \beta}\right) \cdot \frac{\sum_{i \in N} \gamma_{i} \phi_{i}}{\sum_{i \in N} \gamma_{i}} \\
& =\frac{n \beta}{\alpha+n \beta} E P(0, \beta, \phi)+\left(1-\frac{n \beta}{\alpha+n \beta}\right) E P(\infty, \beta, \phi),
\end{aligned}
$$

where

$$
\begin{array}{r}
E P(0, \beta, \phi)=\lim _{\alpha \rightarrow 0} E P(\alpha, \beta, \phi)=\frac{z}{n \beta \sum_{i \in N} \gamma_{i}}, \\
E P(\infty, \beta, \phi)=\lim _{\alpha \rightarrow \infty} E P(\alpha, \beta, \phi)=\frac{\sum_{i \in N} \gamma_{i} \phi_{i}}{\sum_{i \in N} \gamma_{i}} .
\end{array}
$$


Thus,

$$
\frac{\partial}{\partial \alpha} E P(\alpha, \beta, \phi)=\frac{n \beta}{(\alpha+n \beta)^{2}}(E P(\infty, \beta, \phi)-E P(0, \beta, \phi)) .
$$

This implies that, as $\alpha$ increases from zero to infinity, $E P(\alpha, \beta, \phi)$ changes monotonically from $\operatorname{EP}(0, \beta, \phi)$ to $\operatorname{EP}(\infty, \beta, \phi)$. Therefore, $\operatorname{EP}(\alpha, \beta, \phi)$ is strictly increasing in $\alpha$ if and only if $\operatorname{EP}(\infty, \beta, \phi)>E P(0, \beta, \phi)$. Note that $\operatorname{EP}(0, \beta, \phi)=R P(0, \beta, \phi)$; that is, the ambiguity premium is zero when the precision of the stock return is zero because investors ignore ambiguous beliefs on $\theta$ and rely only on private signals. On the other hand, note that $\operatorname{EP}(\infty, \beta, \phi)=A P(\infty, \beta, \phi)$; that is, the risk premium is zero when the precision of the stock return is infinite because investors ignore private signals and rely only on ambiguous beliefs on $\theta$. Since $R P(0, \beta, \phi)$ is decreasing in $\beta$ and $A P(\infty, \beta, \phi)$ is increasing in $\phi_{i}$, if both $\beta$ and $\phi_{i}$ are sufficiently large, then $R P(0, \beta, \phi)<A P(\infty, \beta, \phi)$, by which $E P(\alpha, \beta, \phi)$ is strictly increasing in $\alpha$.

\section{Concluding remarks}

This paper has introduced a tractable model of a stock market under both ambiguity and asymmetric information. We construct the model by combining the model under ambiguity due to Cao et al. (2005) and Easley and O'Hara (2009) and the model under asymmetric information due to Grossman (1976). The notion of rational expectations equilibrium in the standard sense has the problem that some investors demand no stock but the equilibrium price may reflect those investors' private signals. Thus, we introduce the notion of rational expectations equilibrium with endogenous participation. We obtain the equilibrium in a closed form, where the set of participating investors is a solution to an optimization problem.

Using the model, we have identified conditions under which the equity premium increases when limited market participation arises. By the conditions, we can reconcile limited market participation attributed to investors' ambiguity aversion and the large equity premium, which is consistent with the results of Mankiw and Zeldes (1991) and Basak and Cuoco (1998). In our model, limited market participation arises if the precision of the stock return increases, or if the largest deviation of investors' ambiguity increases. We study each case and find that the precision of private signals plays an important role.

When limited market participation arises by an increase in the precision of the stock return, the equity premium increases if and only if the precision of private signals is large enough. This implies that the larger precision of the stock return may result in the 
larger equity premium, whereas, without either ambiguity or private signals, the larger precision of the stock return results in the smaller equity premium.

When limited market participation arises by an increase in the largest deviation of investors' ambiguity, the equity premium increases if and only if the difference between the average ambiguity of participating investors under limited market participation and that under full market participation satisfies one of the following conditions: the difference is larger than some threshold, or the difference is larger than another smaller threshold and the precision of private signals is large enough. One corollary shows that if the average ambiguity of all investors does not increase when limited market participation arises and the precision of private signals is small enough, then the equity premium decreases. Another corollary shows that if the average ambiguity of investors continuing to participate does not decrease when limited market participation arises, then the equity premium increases. In this case, limited market participation, the larger equity premium, and increased ambiguity coexist. This is consistent with anecdotal evidences in the market turmoil in the summer of 2007 spread from the US sub-prime mortgage market: increased investors' uncertainty pointed out by Bernanke $(2007,2008)$ and Roubini (2007), sharply declining risky asset prices, and flight to quality.

\section{Appendix}

\section{A Proof of Lemma 1}

We use the following equation, which can be verified by calculation: for each $S \in 2^{N} \backslash\{\emptyset\}$ and $i \in S$,

$$
\Phi(S)-\Phi(S \backslash\{i\})=\frac{\gamma_{i}}{\sum_{j \in S} \gamma_{j}}\left(\phi_{i}-\Phi(S \backslash\{i\})\right)=\frac{\gamma_{i}}{\sum_{j \in S \backslash\{i\}} \gamma_{j}}\left(\phi_{i}-\Phi(S)\right) .
$$

To show the first half of the lemma, let $M^{*}=\left\{i \in M: \phi_{i}<\min _{M^{\prime} \subseteq M} \Phi\left(M^{\prime}\right)\right\}$, and let $M^{\circ}$ be a minimal set contained in $\arg \min _{M^{\prime} \subseteq M} \Phi\left(M^{\prime}\right)$. We show that $M^{*}=M^{\circ}$. If there exists $i \in M^{*} \backslash M^{\circ}$, then $\phi_{i}<\Phi\left(M^{\circ}\right)$ and thus $\Phi\left(M^{\circ} \cup\{i\}\right)<\Phi\left(M^{\circ}\right)$ by (A.1) with $S=M^{\circ} \cup\{i\}$, which is a contradiction. Thus, $M^{*} \subseteq M^{\circ}$. If there exists $i \in M^{\circ} \backslash M^{*}$, then $\phi_{i} \geq \Phi\left(M^{\circ}\right)$ and thus $\Phi\left(M^{\circ}\right) \geq \Phi\left(M^{\circ} \backslash\{i\}\right)$ by (A.1) with $S=M^{\circ}$, which is a contradiction to the minimality of $M^{\circ}$. Thus, $M^{*} \supseteq M^{\circ}$. Therefore, $M^{*}=M^{\circ}$, which establishes the first half of the lemma.

To show the second half of the lemma, let $M^{*}=\left\{i \in M: \phi_{i}<\min _{M^{\prime} \subseteq M} \Phi\left(M^{\prime}\right)\right\}$ again. By the above argument, $\Phi\left(M^{*}\right)=\min _{M^{\prime} \subseteq M} \Phi\left(M^{\prime}\right)$ and thus $M^{*}=\{i \in M$ : 
$\left.\phi_{i}<\Phi\left(M^{*}\right)\right\}$, which is the "only if" part. To show the "if" part, let $M^{\circ}$ satisfy $M^{\circ}=$ $\left\{i \in M: \phi_{i}<\Phi\left(M^{\circ}\right)\right\}$. Since $\Phi\left(M^{*}\right) \leq \Phi\left(M^{\circ}\right), M^{*} \subseteq M^{\circ}$. Without loss of generality, assume that $M=\{1, \ldots, m\}$ with $\phi_{1} \leq \cdots \leq \phi_{m}$. Then, $M^{*}=\left\{1, \ldots, m^{*}\right\}$ and $M^{\circ}=\left\{1, \ldots, m^{\circ}\right\}$ with $m^{*} \leq m^{\circ} \leq m$. Let $S_{k}=\{1, \ldots, k\}$ for each $k \in M$. Since $\Phi\left(M^{*}\right)=\Phi\left(S_{m^{*}}\right) \leq \phi_{m^{*}+1}$, we have $\Phi\left(S_{m^{*}}\right) \leq \Phi\left(S_{m^{*}+1}\right)$ and $\Phi\left(S_{m^{*}+1}\right) \leq \phi_{m^{*}+1} \leq$ $\phi_{m^{*}+2}$ by (A.1) with $S=S_{m^{*}+1}$ and $i=m^{*}+1$. Then, by (A.1) with $S=S_{m^{*}+2}$ and $i=m^{*}+2$, we have $\Phi\left(S_{m^{*}+1}\right) \leq \Phi\left(S_{m^{*}+2}\right)$ and $\Phi\left(S_{m^{*}+2}\right) \leq \phi_{m^{*}+2} \leq \phi_{m^{*}+3}$. Repeating this, we find that $\Phi\left(S_{k}\right) \leq \phi_{k}$ for all $k \geq m^{*}+1$. This implies that $m^{*}=m^{\circ}$ and $M^{*}=M^{\circ}$.

\section{B Proof of Proposition 1}

To establish Proposition 1, we take the strategy used by Grossman (1976). That is, we obtain a pooled information equilibrium, and then, show that it is a rational expectations equilibrium.

A pooled information equilibrium for $M \in 2^{N} \backslash\{\emptyset\}$ is a price function $p_{M}$ for $M$ such that $\tilde{p}=p_{M}\left(\tilde{s}_{M}\right)$ is a market clearing price when each investor receives common information $\tilde{s}_{M}$; that is,

$$
\sum_{i \in M} d_{i}\left(\tilde{p} \mid \tilde{s}_{M}\right)=z \text { where } d_{i}\left(\tilde{p} \mid \tilde{s}_{M}\right) \in \arg \max _{d_{i} \in \mathbb{R}} \min _{\theta^{\prime} \in \Theta_{i}} E_{\theta^{\prime}}\left[u_{i}\left(w_{0 i}+(\tilde{v}-\tilde{p}) d_{i}\right) \mid \tilde{s}_{M}\right]
$$

Lemma A The price function $p_{M}$ given in Proposition 1 is the unique pooled information equilibrium for $M$. Furthermore, $d_{i}\left(\tilde{p} \mid \tilde{s}_{M}\right)>0$ for each $i \in M^{*}$ and $d_{i}\left(\tilde{p} \mid \tilde{s}_{M}\right)=0$ for each $i \in M \backslash M^{*}$, where $\tilde{p}=p_{M}\left(\tilde{s}_{M}\right)$.

Proof. Let $p_{M}$ be a pooled information equilibrium for $M$ and let $\tilde{p}=p_{M}\left(\tilde{s}_{M}\right)$. Note that $\sum_{i \in M} \tilde{s}_{i} / m$ is sufficient for $\tilde{v}$ and that $\left(\tilde{v}, \sum_{i \in M} \tilde{s}_{i} / m\right)$ is normally distributed with mean $(\theta, \theta)$ and covariance matrix

$$
\left(\begin{array}{cc}
\alpha^{-1} & \alpha^{-1} \\
\alpha^{-1} & \alpha^{-1}+\beta^{-1} m^{-1}
\end{array}\right) .
$$

Thus, the conditional probability distribution of $\tilde{v}$ given $\sum_{i \in M} \tilde{s}_{i} / m$ is normal with the following conditional mean and variance:

$$
E_{\theta}\left[\tilde{v} \mid \sum_{i \in M} \tilde{s}_{i} / m\right]=\frac{\alpha}{\alpha+m \beta} \theta+\frac{m \beta}{\alpha+m \beta} \frac{\sum_{i \in M} \tilde{s}_{i}}{m}, V_{\theta}\left[\tilde{v} \mid \sum_{i \in M} \tilde{s}_{i} / m\right]=\frac{1}{\alpha+m \beta} .
$$


Since $\sum_{i \in M} \tilde{s}_{i} / m$ is sufficient for $\tilde{v}, E_{\theta}\left[\tilde{v} \mid \tilde{s}_{M}\right]=E_{\theta}\left[\tilde{v} \mid \sum_{i \in M} \tilde{s}_{i} / m\right]$ and $V_{\theta}\left[\tilde{v} \mid \tilde{s}_{M}\right]=$ $V_{\theta}\left[\tilde{v} \mid \sum_{i \in M} \tilde{s}_{i} / m\right]$, which establishes (3). Then,

$$
\begin{aligned}
E_{\theta}\left[u_{i}\left(w_{0 i}+(\tilde{v}-\tilde{p}) d_{i}\right) \mid \tilde{s}_{M}\right] & =-E_{\theta}\left[\exp \left(-\left(w_{0 i}+(\tilde{v}-\tilde{p}) d_{i}\right) / \gamma_{i}\right) \mid \tilde{s}_{M}\right] \\
& =-\exp \left(-w_{0 i} / \gamma_{i}-\left(E_{\theta}\left[\tilde{v} \mid \tilde{s}_{M}\right]-\tilde{p}\right) d_{i} / \gamma_{i}+V_{\theta}\left[\tilde{v} \mid \tilde{s}_{M}\right] d_{i}^{2} /\left(2 \gamma_{i}^{2}\right)\right)
\end{aligned}
$$

and

$$
\begin{aligned}
\arg \max _{d_{i}} \min _{\theta^{\prime} \in \Theta_{i}} E_{\theta^{\prime}}\left[u_{i}\left(w_{0 i}+(\tilde{v}-\tilde{p}) d_{i}\right) \mid \tilde{s}_{M}\right] \\
=\arg \max _{d_{i}} \min _{\theta^{\prime} \in \Theta_{i}}\left(E_{\theta^{\prime}}\left[\tilde{v} \mid \tilde{s}_{M}\right]-\tilde{p}\right) d_{i}-V_{\theta^{\prime}}\left[\tilde{v} \mid \tilde{s}_{M}\right] d_{i}^{2} /\left(2 \gamma_{i}\right) \\
=\arg \max _{d_{i}} \min _{\theta^{\prime} \in \Theta_{i}}\left(E_{\theta^{\prime}}\left[\tilde{v} \mid \tilde{s}_{M}\right]-\tilde{p}\right) d_{i}-d_{i}^{2} /\left(2 \gamma_{i}(\alpha+m \beta)\right) .
\end{aligned}
$$

We first solve the inner minimization. Note that

$$
\begin{aligned}
f\left(d_{i}\right) & \equiv \min _{\theta^{\prime} \in \Theta_{i}}\left(E_{\theta^{\prime}}\left[\tilde{v} \mid \tilde{s}_{M}\right]-\tilde{p}\right) d_{i}-d_{i}^{2} /\left(2 \gamma_{i}(\alpha+m \beta)\right) \\
& = \begin{cases}\left(E_{\theta_{i}}\left[\tilde{v} \mid \tilde{s}_{M}\right]-\tilde{p}\right) d_{i}-d_{i}^{2} /\left(2 \gamma_{i}(\alpha+m \beta)\right) & \text { if } d_{i}>0, \\
\left(E_{\bar{\theta}_{i}}\left[\tilde{v} \mid \tilde{s}_{M}\right]-\tilde{p}\right) d_{i}-d_{i}^{2} /\left(2 \gamma_{i}(\alpha+m \beta)\right) & \text { if } d_{i}<0 \\
0 & \text { if } d_{i}=0 .\end{cases}
\end{aligned}
$$

Thus, $f^{\prime}\left(d_{i}\right)$ exists for $d_{i} \neq 0$ and

$$
f^{\prime}\left(d_{i}\right)= \begin{cases}E_{\underline{\theta}_{i}}\left[\tilde{v} \mid \tilde{s}_{M}\right]-\tilde{p}-d_{i} /\left(\gamma_{i}(\alpha+m \beta)\right) & \text { if } d_{i}>0, \\ E_{\bar{\theta}_{i}}\left[\tilde{v} \mid \tilde{s}_{M}\right]-\tilde{p}-d_{i} /\left(\gamma_{i}(\alpha+m \beta)\right) & \text { if } d_{i}<0 .\end{cases}
$$

Since $E_{\underline{\theta}_{i}}\left[\tilde{v} \mid \tilde{s}_{M}\right] \leq E_{\bar{\theta}_{i}}\left[\tilde{v} \mid \tilde{s}_{M}\right], f^{\prime}\left(d_{i}\right)$ is decreasing in $d_{i}$. Therefore, we have

$$
d_{i}\left(\tilde{p} \mid \tilde{s}_{M}\right)= \begin{cases}\gamma_{i}(\alpha+m \beta)\left(E_{\underline{\theta}_{i}}\left[\tilde{v} \mid \tilde{s}_{M}\right]-\tilde{p}\right) & \text { if } \tilde{p}<E_{\underline{\theta}_{i}}\left[\tilde{v} \mid \tilde{s}_{M}\right] \\ \gamma_{i}(\alpha+m \beta)\left(E_{\bar{\theta}_{i}}\left[\tilde{v} \mid \tilde{s}_{M}\right]-\tilde{p}\right) & \text { if } \tilde{p}>E_{\bar{\theta}_{i}}\left[\tilde{v} \mid \tilde{s}_{M}\right] \\ 0 & \text { otherwise. }\end{cases}
$$

Let $\tilde{p}$ be a market clearing price. If $\tilde{p}>E_{\bar{\theta}_{i}}\left[\tilde{v} \mid \tilde{s}_{M}\right]$ for some $i \in M$, then $\tilde{p}>$ $E_{\bar{\theta}_{i}}\left[\tilde{v} \mid \tilde{s}_{M}\right] \geq E_{\underline{\theta}_{j}}\left[\tilde{v} \mid \tilde{s}_{M}\right]$ for all $j \in M$ because $\bar{\theta}_{i} \geq \underline{\theta}_{j}$ for all $j \in N$ by the assumption $\bigcap_{i \in N} \Theta_{i} \neq \emptyset$. This implies that the total demand for the risky asset is strictly negative and $\tilde{p}$ is not a market clearing price. Therefore, $\tilde{p} \leq E_{\bar{\theta}_{i}}\left[\tilde{v} \mid \tilde{s}_{M}\right]$ for all $i \in M$ and $\tilde{p}<E_{\underline{\theta}_{i}}\left[\tilde{v} \mid \tilde{s}_{M}\right]$ for some $i \in M$; that is, $d_{i}\left(\tilde{p} \mid \tilde{s}_{M}\right) \geq 0$ for all $i \in M$ and $d_{i}\left(\tilde{p} \mid \tilde{s}_{M}\right)>0$ for some $i \in M$. Let

$$
M(\tilde{p}) \equiv\left\{i \in M: d_{i}\left(\tilde{p} \mid \tilde{s}_{M}\right)>0\right\}=\left\{i \in M: \tilde{p}<E_{\underline{\theta}_{i}}\left[\tilde{v} \mid \tilde{s}_{M}\right]\right\}
$$


Then, the market clearing condition is

$$
\sum_{i \in M} d_{i}\left(\tilde{p} \mid \tilde{s}_{M}\right)=\sum_{i \in M(\tilde{p})} \gamma_{i}(\alpha+m \beta)\left(E_{\underline{\theta}_{i}}\left[\tilde{v} \mid \tilde{s}_{M}\right]-\tilde{p}\right)=z
$$

and thus

$$
\begin{aligned}
\tilde{p} & =\frac{\sum_{i \in M(\tilde{p})} \gamma_{i} E_{\underline{\theta}_{i}}\left[\tilde{v} \mid \tilde{s}_{M}\right]}{\sum_{i \in M(\tilde{p})} \gamma_{i}}-\frac{z}{(\alpha+m \beta) \sum_{i \in M(\tilde{p})} \gamma_{i}} \\
& =E_{\theta}\left[\tilde{v} \mid \tilde{s}_{M}\right]-\frac{z}{(\alpha+m \beta) \sum_{i \in M(\tilde{p})} \gamma_{i}}-\frac{\alpha \sum_{i \in M(\tilde{p})} \gamma_{i} \phi_{i}}{(\alpha+m \beta) \sum_{i \in M(\tilde{p})} \gamma_{i}} \\
& =E_{\theta}\left[\tilde{v} \mid \tilde{s}_{M}\right]-\frac{\alpha}{\alpha+m \beta} \Phi(M(\tilde{p})) .
\end{aligned}
$$

This implies that

$$
\begin{aligned}
E_{\underline{\theta}_{i}}\left[\tilde{v} \mid \tilde{s}_{M}\right]-\tilde{p} & =E_{\theta}\left[\tilde{v} \mid \tilde{s}_{M}\right]-\tilde{p}-\frac{\alpha \phi_{i}}{\alpha+m \beta} \\
& =\frac{\alpha}{\alpha+m \beta} \Phi(M(\tilde{p}))-\frac{\alpha \phi_{i}}{\alpha+m \beta} \\
& =\frac{\alpha}{\alpha+m \beta}\left(\Phi(M(\tilde{p}))-\phi_{i}\right) .
\end{aligned}
$$

Therefore, $M(\tilde{p})=\left\{i \in M: \phi_{i}<\Phi(M(\tilde{p}))\right\}=M^{*}$ by (B.2) and Lemma 1. Plugging $M(\tilde{p})=M^{*}$ into (B.3), we obtain (2) since $\Phi\left(M^{*}\right)=\min _{M^{\prime} \subseteq M} \Phi\left(M^{\prime}\right)$ by Lemma 1 . Finally, by (B.2), $d_{i}\left(\tilde{p} \mid \tilde{s}_{M}\right)>0$ for each $i \in M^{*}$ and $d_{i}\left(\tilde{p} \mid \tilde{s}_{M}\right)=0$ for each $i \in M \backslash M^{*}$.

We are ready to prove Proposition 1 . Let $p_{M}$ be the price function given in (2) and let $\tilde{p}=p_{M}\left(\tilde{s}_{M}\right)$. Note that $\sum_{i \in M} \tilde{s}_{i} / m$ can be written as a linear function of $\tilde{p}$ by $(2)$ and (3). Since $\sum_{i \in M} \tilde{s}_{i} / m$ is sufficient for $\tilde{v}$, so is $\tilde{p}$, and thus

$E_{\theta^{\prime}}\left[u_{i}\left(w_{0 i}+(\tilde{v}-\tilde{p}) d_{i}\right) \mid \tilde{s}_{M}\right]=E_{\theta^{\prime}}\left[u_{i}\left(w_{0 i}+(\tilde{v}-\tilde{p}) d_{i}\right) \mid\left(\tilde{s}_{i}, \tilde{p}\right)\right]=E_{\theta^{\prime}}\left[u_{i}\left(w_{0 i}+(\tilde{v}-\tilde{p}) d_{i}\right) \mid \tilde{I}_{i}\right]$

for each $\theta^{\prime} \in \Theta_{i}$, where $\tilde{I}_{i}=\left(\tilde{s}_{i}, \tilde{p}\right)$. Therefore, $d_{i}\left(\tilde{p} \mid \tilde{I}_{i}\right)=d_{i}\left(\tilde{p} \mid \tilde{s}_{M}\right)$. Since $p_{M}$ is a pooled information equilibrium for $M$ by Lemma A, $\sum_{i \in M} d_{i}\left(\tilde{p} \mid \tilde{I}_{i}\right)=\sum_{i \in M} d_{i}\left(\tilde{p} \mid \tilde{s}_{M}\right)=z$, which implies that $p_{M}$ is a rational expectations equilibrium for $M$. Also by Lemma A, $d_{i}\left(\tilde{p} \mid \tilde{I}_{i}\right)=d_{i}\left(\tilde{p} \mid \tilde{s}_{M}\right)>0$ for each $i \in M^{*}$ and $d_{i}\left(\tilde{p} \mid \tilde{I}_{i}\right)=d_{i}\left(\tilde{p} \mid \tilde{s}_{M}\right)=0$ for each $i \in M \backslash M^{*}$.

\section{Proof of Proposition 2}

In establishing Proposition 2, the following lemma plays an essential role. 
Lemma B For each $M \in 2^{N} \backslash\{\emptyset\}$, let $p_{M}$ be the rational expectations equilibrium for $M$ given in Proposition 1. Then, $p_{M}$ satisfies the first and second conditions in Definition 2 if and only if $M=N^{*}$.

Proof. We first show the "if" part. Note that $\Phi\left(N^{*}\right)=\min _{N^{\prime} \subseteq N} \Phi\left(N^{\prime}\right)=\min _{N^{\prime} \subseteq N^{*}} \Phi\left(N^{\prime}\right)$ and that $N^{*}=\left\{i \in N: \phi_{i}<\Phi\left(N^{*}\right)\right\}=\left\{i \in N^{*}: \phi_{i}<\Phi\left(N^{*}\right)\right\}$ by Lemma 1 . Let $\tilde{p}=p_{N^{*}}\left(\tilde{s}_{N^{*}}\right)$. Suppose that $i \in N^{*}$ and $\tilde{I}_{i}=\left(\tilde{s}_{i}, \tilde{p}\right)$. Since $M=N^{*}$ implies $M^{*}=\left\{i \in N^{*}: \phi_{i}<\min _{N^{\prime} \subseteq N^{*}} \Phi\left(N^{\prime}\right)\right\}=\left\{i \in N^{*}: \phi_{i}<\Phi\left(N^{*}\right)\right\}=N^{*}, d_{i}\left(\tilde{p} \mid \tilde{I}_{i}\right)>0$ by Proposition 1, which implies the first condition in Definition 2. Suppose that $i \notin N^{*}$ and $\tilde{I}_{i}=\tilde{p}$. Since $\tilde{p}$ is sufficient for $\tilde{v}, E_{\theta^{\prime}}\left[u_{i}\left(w_{0 i}+(\tilde{v}-\tilde{p}) d_{i}\right) \mid \tilde{I}_{i}\right]=E_{\theta^{\prime}}\left[u_{i}\left(w_{0 i}+(\tilde{v}-\tilde{p}) d_{i}\right) \mid \tilde{s}_{N^{*}}\right]$ for each $\theta_{i}^{\prime} \in \Theta_{i}$ and thus $d_{i}\left(\tilde{p} \mid \tilde{I}_{i}\right)=d_{i}\left(\tilde{p} \mid \tilde{s}_{N^{*}}\right)$, which is given by (B.1) with $M=N^{*}$ and $m=n^{*} \equiv\left|N^{*}\right|$. By (2) and (3),

$$
\begin{aligned}
E_{\underline{\theta}_{i}}\left[\tilde{v} \mid \tilde{s}_{N^{*}}\right]-p_{N^{*}}\left(\tilde{s}_{N^{*}}\right) & =E_{\theta}\left[\tilde{v} \mid \tilde{s}_{N^{*}}\right]-p_{N^{*}}\left(\tilde{s}_{N^{*}}\right)-\frac{\alpha \phi_{i}}{\alpha+n^{*} \beta} \\
& =\frac{\alpha}{\alpha+n^{*} \beta}\left(\min _{N^{\prime} \subseteq N^{*}} \Phi\left(N^{\prime}\right)-\phi_{i}\right) \\
& =\frac{\alpha}{\alpha+n^{*} \beta}\left(\Phi\left(N^{*}\right)-\phi_{i}\right) \leq 0
\end{aligned}
$$

since $i \notin N^{*}=\left\{j \in N: \phi_{j}<\Phi\left(N^{*}\right)\right\}$. Note that $\bar{\theta}_{i} \geq \underline{\theta}_{j}$ for all $j \in N$ by the assumption $\bigcap_{i \in N} \Theta_{i} \neq \emptyset$. Thus,

$$
\begin{aligned}
E_{\bar{\theta}_{i}}\left[\tilde{v} \mid \tilde{s}_{N^{*}}\right]-p_{N^{*}}\left(\tilde{s}_{N^{*}}\right) & \geq \max _{j \in N} E_{\underline{\theta}_{j}}\left[\tilde{v} \mid \tilde{s}_{N^{*}}\right]-p_{N^{*}}\left(\tilde{s}_{N^{*}}\right) \\
& =\max _{j \in N} \frac{\alpha}{\alpha+n^{*} \beta}\left(\Phi\left(N^{*}\right)-\phi_{j}\right) \\
& =\frac{\alpha}{\alpha+n^{*} \beta}\left(\Phi\left(N^{*}\right)-\min _{j \in N} \phi_{j}\right)>0
\end{aligned}
$$

since $\arg \min _{j \in N} \phi_{j} \in\left\{i \in N: \phi_{i}<\Phi\left(N^{*}\right)\right\}=N^{*}$. Therefore, by (B.1), $d_{i}\left(\tilde{p} \mid \tilde{I}_{i}\right)=$ $d_{i}\left(\tilde{p} \mid \tilde{s}_{N^{*}}\right)=0$, which implies the second condition in Definition 2.

To show the "only if" part, suppose that $p_{M}$ satisfies the first and second conditions in Definition 2. We show that $M=N^{*}$. Let $\tilde{p}=p_{M}\left(\tilde{s}_{M}\right)$ and $m=|M|$. By the first condition, if $i \in M$ and $\tilde{I}_{i}=\left(\tilde{s}_{i}, \tilde{p}\right)$, then $d_{i}\left(\tilde{p} \mid \tilde{I}_{i}\right) \neq 0$. This and Proposition 1 imply that $M^{*}=M$. By the second condition, if $i \notin M$ and $\tilde{I}_{i}=\tilde{p}$, then $d_{i}\left(\tilde{p} \mid \tilde{I}_{i}\right)=0$. Since $\tilde{p}$ is sufficient for $\tilde{v}, d_{i}\left(\tilde{p} \mid \tilde{I}_{i}\right)=d_{i}\left(\tilde{p} \mid \tilde{s}_{M}\right)$, which is given by (B.1). If there exists $i \in N^{*} \backslash M$, then, by (2) and (3),

$$
\begin{aligned}
E_{\underline{\theta}_{i}}\left[\tilde{v} \mid \tilde{s}_{M}\right]-p_{M}\left(\tilde{s}_{M}\right) & =\frac{\alpha}{\alpha+m \beta}\left(\min _{M^{\prime} \subseteq M} \Phi\left(M^{\prime}\right)-\phi_{i}\right) \\
& \geq \frac{\alpha}{\alpha+m \beta}\left(\min _{N^{\prime} \subseteq N} \Phi\left(N^{\prime}\right)-\phi_{i}\right)>0
\end{aligned}
$$


since $i \in N^{*}$, which implies that $d_{i}\left(\tilde{p} \mid \tilde{I}_{i}\right)=d_{i}\left(\tilde{p} \mid \tilde{s}_{M}\right)>0$ by (B.1). This is a contradiction and we must have $N^{*} \subseteq M$. Therefore, $M=M^{*}=\left\{i \in M: \phi_{i}<\min _{M^{\prime} \subseteq M} \Phi\left(M^{\prime}\right)\right\}=$ $\left\{i \in M: \phi_{i}<\Phi\left(N^{*}\right)\right\}=N^{*}$ by Lemma 1 .

We are ready to prove Proposition 2. By Lemma B, $p_{N^{*}}$ is the unique price function in $\left\{p_{M}\right\}_{M \in 2^{N} \backslash\{\emptyset\}}$ satisfying the first and second conditions in Definition 2. Thus, it remains to show that $p_{N^{*}}$ satisfies the third condition in Definition 2. For $M \in 2^{N} \backslash\{\emptyset\}$ with $N^{*} \subsetneq M$, let $\tilde{p}=p_{M}\left(\tilde{s}_{M}\right)$. Suppose that $i \in M \backslash N^{*}$ and $\tilde{I}_{i}=\left(\tilde{s}_{i}, \tilde{p}\right)$. Then, $d_{i}\left(\tilde{p} \mid \tilde{I}_{i}\right)=0$ by Proposition 1 since $M^{*}=N^{*}$, which is the third condition in Definition 2.

\section{Rational expectations equilibria in the standard sense}

In section 4, we study comparative statics of the equity premium under rational expectations equilibria with endogenous participation. In this appendix, we study it under rational expectations equilibria in the standard sense, and examine how the results change if non-participating investors receive private signals and the equilibrium prices reflect all of them. We show that, also in this case, the equity premium can increase when limited market participation arises.

Let $p_{N}$ be the rational expectation equilibrium for $N$ given by Proposition 1, which is a rational expectation equilibrium in the standard sense. Also in this equilibrium, $N^{*}(\alpha, \phi)=\left\{i \in N: \phi_{i}<\min _{N^{\prime} \subseteq N} \Phi\left(N^{\prime} \mid \alpha, \phi\right)\right\}$ is the set of participating investors. Hence, limited market participation arises under $p_{N}$ if and only if it arises under $p_{N^{*}}$. The equity premium under $p_{N}$ is

$$
E P_{N}(\alpha, \beta, \phi) \equiv E_{\theta}\left[\tilde{v} \mid \tilde{s}_{N}\right]-p_{N}\left(\tilde{s}_{N}\right) .
$$

We first consider limited market participation induced by a change in $\phi$. The following is the counterpart of Proposition 3.

Proposition A Let $\alpha, \phi, \phi^{\prime}$ be such that $N^{*}\left(\alpha, \phi^{\prime}\right)=N^{\prime} \subsetneq N=N^{*}(\alpha, \phi)$ with $n^{\prime}=$ $\left|N^{\prime}\right|$. If $\delta\left(\phi, \phi^{\prime}\right)>\Delta^{*}$, then $E P_{N}\left(\alpha, \beta, \phi^{\prime}\right)>E P_{N}(\alpha, \beta, \phi)$. If $\delta\left(\phi, \phi^{\prime}\right)<\Delta^{*}$, then $E P_{N}\left(\alpha, \beta, \phi^{\prime}\right)<E P_{N}(\alpha, \beta, \phi)$. If $\delta\left(\phi, \phi^{\prime}\right)=\Delta^{*}$, then $E P_{N}\left(\alpha, \beta, \phi^{\prime}\right)=E P_{N}(\alpha, \beta, \phi)$.

Proof. The following calculation proves the proposition:

$$
E P_{N}\left(\alpha, \beta, \phi^{\prime}\right)-E P_{N}(\alpha, \beta, \phi)=\frac{\alpha\left(\Phi^{*}\left(\alpha, \phi^{\prime}\right)-\Phi^{*}(\alpha, \phi)\right)}{\alpha+n \beta}=\frac{\alpha\left(\delta\left(\phi, \phi^{\prime}\right)-\Delta^{*}\right)}{\alpha+n \beta} . \mathbf{~}
$$

Note that the above condition is the same as that in Corollary 4. Since information contained in the equilibrium prices are the same for both full market participation and 
limited market participation, private signals have no direct role in the change of the equity premium, which is different from the case considered in Proposition 3 . The equity premium, however, increases when limited market participation arises if $\delta\left(\phi, \phi^{\prime}\right)>\Delta^{*}$.

We next consider limited market participation induced by an increase in $\alpha$. The following is the counterpart of Proposition 7.

Proposition B Let $\alpha, \alpha^{\prime}, \phi$ be such that $\alpha^{\prime}>\alpha$ and $N^{*}\left(\alpha^{\prime}, \phi\right)=N^{\prime} \subseteq N=N^{*}(\alpha, \phi)$ with $n^{\prime}=\left|N^{\prime}\right|$. Assume that $A P\left(\alpha^{\prime}, \beta, \phi\right)>0$. Define

$$
C \equiv \frac{\alpha \alpha^{\prime}\left(\Phi^{*}(\alpha, \phi)-\Phi^{*}\left(\alpha^{\prime}, \phi\right)\right)}{n\left(\alpha^{\prime} \Phi^{*}\left(\alpha^{\prime}, \phi\right)-\alpha \Phi^{*}(\alpha, \phi)\right)} .
$$

If $\beta>C$, then $E P_{N}\left(\alpha^{\prime}, \beta, \phi\right)>E P_{N}(\alpha, \beta, \phi)$. If $\beta<C$, then $E P_{N}\left(\alpha^{\prime}, \beta, \phi\right)<$ $E P_{N}(\alpha, \beta, \phi)$. If $\beta=C$, then $E P_{N}\left(\alpha^{\prime}, \beta, \phi\right)=E P_{N}(\alpha, \beta, \phi)$. Furthermore, $C>0$.

Proof. Recall that $\Phi^{*}(\alpha, \phi)$ is strictly decreasing in $\alpha$ and that $\alpha \Phi^{*}(\alpha, \phi)$ is strictly increasing in $\alpha$ (see the proof of Proposition 7). This implies $C>0$, and the following calculation proves the proposition:

$$
E P_{N}\left(\alpha^{\prime}, \beta, \phi\right)-E P_{N}(\alpha, \beta, \phi)=\frac{n\left(\alpha^{\prime} \Phi^{*}\left(\alpha^{\prime}, \phi\right)-\alpha \Phi^{*}(\alpha, \phi)\right)(\beta-C)}{(\alpha+n \beta)\left(\alpha^{\prime}+n \beta\right)}
$$

In spite that private signals have no direct role in the change of the equity premium, the larger precision of the stock return results in the larger equity premium if $\beta>C$. The intuition behind this result is exactly the same as that behind Proposition 7 for the case with $N^{*}(\alpha, \phi)=N^{*}\left(\alpha^{\prime}, \phi\right)=N$, which is discussed at the end of section 4 .

\section{References}

Ahn, D. (2007) Hierarchies of ambiguous beliefs, Journal of Economic Theory 136, 286301.

Allen, F. and Gale, D. (1994) Limited market participation and volatility of asset prices, American Economic Review 84, 933-955.

Anderson. E., Ghysels, E. and Juergens, J. (2009) The impact of risk and uncertainty on expected returns, Journal of Financial Economics 94, 233-263.

Attanasio, O., Banks, J. and Tanner, S. (2002) Asset holding and consumption volatility, Journal of Political Economy 110, 771-792.

Aumann, R. J. (1976) Agreeing to disagree, Annals of Statistics 4, 1236-1239. 
Balasko, Y., Cass, D. and Shell, K. (1995) Market participation and sunspot equilibria, Review of Economic Studies 62, 491-512.

Balasko, Y., Cass, D. and Siconolfi, P. (1990) The structure of financial equilibrium with exogenous yields: the case of restricted participation, Journal of Mathematical Economics 19, 195-216.

Basak, S. and Cuoco, D. (1998) An equilibrium model with restricted stock market participation. Review of Financial Studies 11, 309-341.

Bernanke, B. (2007) Subprime mortgage lending and mitigating foreclosures, testimony before the Committee on Financial Services, U.S. House of Representatives, September 20 .

Bernanke, B. (2008) Financial markets, the economic outlook, and monetary policy, remarks at the Women in Housing and Finance and Exchequer Club Joint Luncheon, Washington DC, January 10.

Billot, A., Chateauneuf, A., Gilboa, I. and Tallon, J.- M. (2000) Sharing beliefs: between agreeing and disagreeing, Econometrica 68, 685-694.

Bollerslev, T., Chou, R. Y. and Kroner, K. F. (1992) ARCH modeling in finance: a review of the theory and empirical evidence, Journal of Econometrics 52, 5-59.

Brav, A., Constantinides, G. and Geczy, C. (2002) Asset pricing with heterogeneous consumers and limited participation: empirical evidence, Journal of Political Economy 110, $793-824$.

Caballero, R. J. and Krishnamurthy, A. (2008) Collective risk management in a flight to quality episode, Journal of Finance 63, 2195-2230.

Cao, H., Wang, T. and Zhang, H. (2005) Model uncertainty, limited market participation, and asset prices, Review of Financial Studies 18, 1219-1251.

Caskey, J. A. (2009) Information in equity markets with ambiguity-averse investors, Review of Financial Studies 22, 3595-3627.

Chen, Z. and Epstein, L. (2002) Ambiguity, risk, and asset returns in continuous time, Econometrica 70, 1403-1443.

Condie, S. and Ganguli, J. (2008) Ambiguity and rational expectations equilibria, unpublished working paper, Brigham Young University, University of Cambridge. 
Cuny, C. J. (1993) The role of liquidity in futures markets innovation, Review of Financial Studies 6, 57-78.

DeMarzo, P. and Skiadas, C. (1998) Aggregation, determinacy, and information efficiency for a class of economies with asymmetric information, Journal of Economic Theory 80, 123-152.

Dow, J., Madrigal, V. and Werlang, S. (1990) Preference, common knowledge and speculative trade, Getulio Vargas Foundation Economics Working Paper 149.

Dow, J. and Werlang, S. (1992) Uncertainty aversion, risk aversion, and the optimal choice of portfolio, Econometrica 60, 197-204.

Easley, D. and O'Hara, M. (2004) Information and the cost of capital, Journal of Finance 59, 1553-1583.

Easley, D. and O'Hara, M. (2009) Ambiguity and nonparticipation: the role of regulation, Review of Financial Studies 22, 1817-1843.

Eichberger, J. and Kelsey, D. (1996) Uncertainty aversion and dynamic consistency, International Economic Review 37, 625-640.

Epstein, L. G. and Le Breton, M. (1993) Dynamically consistent beliefs must be Bayesian, Journal of Economic Theory 61, 1-22.

Epstein, L. G. and Miao, J. (2003) A two-person dynamic equilibrium under ambiguity, Journal of Economic Dynamics and Control 27, 1253-1288.

Epstein, L. G. and Schneider, M. (2003) Recursive multiple priors, Journal of Economic Theory 113, 1-31.

Epstein, L. G. and Schneider, M. (2007) Learning under ambiguity, Review of Economic Studies 74, 1275-1303.

Epstein, L. G. and Schneider, M. (2008) Ambiguity, information quality and asset prices, Journal of Finance 63, 197-228.

Epstein, L. G. and Wang, T. (1994) Intertemporal asset pricing under Knightian uncertainty, Econometrica 62, 283-322.

Epstein, L. G. and Wang, T. (1996) "Beliefs about beliefs" without probabilities, Econometrica 64, 1343-1373. 
Erabas, S. N. and Mirakhor, A (2007) The equity premium puzzle, ambiguity aversion, and institutional quality, IMF Working Paper 07/230.

Fagin, R. and Halpern, J. (1990) A new approach to updating beliefs, in: P. P. Bonissone, M. Henrion, L. N. Kanal and J. F. Lemmer (eds.), Proceedings of the Sixth Annual Conference on Uncertainty in Artificial Intelligence, Elsevier, New York, pp. 317-325.

Gilboa, I. and Schmeidler, D. (1989) Maxmin expected utility with a non-unique prior, Journal of Mathematical Economics 18, 141-153.

Grossman, S. (1976) On the efficiency of competitive stock markets where investors have diverse information, Journal of Finance 2, 573-584.

Grossman, S. and Stiglitz, J. (1980) On the impossibility of informationally efficient markets, American Economic Review 70, 393-408.

Halevy, Y. (2004) The possibility of speculative trade between dynamically consistent agents, Games and Economic Behavior 46, 189-198.

Horie, M. (2007) A general update rule for convex capacities, KIER Discussion Paper 644.

Hughes, J., Liu, J. and Liu, J. (2007) Information, diversification, and cost of capital, Accounting Review 82, 705-729.

Jaffray, J.-Y. (1992) Bayesian updating and belief functions, IEEE Transactions on Systems, Man, and Cybernetics 22, 1144-1152.

Kajii, A. and Ui, T. (2005) Incomplete information games with multiple priors, Japanese Economic Review 56, 332-351.

Kajii, A. and Ui, T. (2009) Interim efficient allocations under uncertainty, Journal of Economic Theory 144, 337-353.

Klibanoff, P., Marinacci, M. and Mukerji, S. (2005) A smooth model of decision making under ambiguity, Econometrica 73, 1849-1892.

Krebs, T. (2007) Rational expectations equilibrium and the strategic choice of costly information, Journal of Mathematical Economics 43, 532-548.

Kreps, D. (1977) A note on "fulfilled expectations" equilibria, Journal of Economic Theory 14, 32-43. 
Lambert, R., Leuz, C. and Verrecchia, R. (2006) Information asymmetry, information precision, and the cost of capital, Wharton Financial Institutions Center Working Paper 06-21.

Liu, J., Longstaff, F. and Pan, J. (2003) Dynamic asset allocation with event risk, Journal of Finance 58, 231-259.

Liu, J., Pan, J. and Wang, T. (2005) An equilibrium model of rare-event premia and its implication for option smirks, Review of Financial Studies 18, 131-164.

Ma, C. (2001) No trade theorem under Knightian uncertainty with general preferences, Theory and Decision 51, 173-181.

Maenhout, P. J. (2004) Robust portfolio rules and asset pricing, Review of Financial Studies 17, 951-983.

Mankiw, N. G. and Zeldes, S. P. (1991) The consumption of stockholders and nonstockholders, Journal of Financial Economics 29, 97-112.

Mehra, R. and Prescott, E. C. (1985) The equity premium: a puzzle, Journal of Monetary Economics 15, 145-161.

Mehra, R. and Prescott, E. C. (2003) The equity premium in retrospect, in: G. M. Constantinides, M. Harris and R. M. Stulz (eds.), Handbook of the Economics of Finance, North Holland, Amsterdam, pp. 890-938.

Merten, R. (1987) A simple model of capital market equilibrium with incomplete information, Journal of Finance 42, 483-510.

Milgrom, P. and Stokey, N. (1982) Information, trade and common knowledge, Journal of Economic Theory 26, 17-27.

Muendler, M.-A. (2007) The possibility of informationally efficient markets, Journal of Economic Theory 133, 467-483.

Ozsoylev, H. and Werner, J. (2006) Liquidity and asset prices in rational expectations equilibrium with ambiguous information, unpublished working paper, University of Oxford, University of Minnesota .

Pires, C. P. (2002) A rule for updating ambiguous beliefs, Theory and Decision 53, $137-152$. 
Rigotti, L., Shannon, C. and Strzalecki, T. (2008) Subjective beliefs and ex ante trade, Econometrica 76, 1167-1190.

Roubini, N. (2007) Current market turmoil: non-priceable Knightian "uncertainty" rather than priceable market "risk", Nouriel Roubini's Blog, http://www.rgemonitor.com/blog/roubini/210688 (accessed October 8, 2007).

Routledge, B. and Zin, S. (2009) Model uncertainty and liquidity, Review of Economic Dynamics 12, 543-566.

Sarin, R. and Wakker, P. (1998) Dynamic choice and nonexpected utility, Journal of Risk and Uncertainty 17, 87-119.

Shapiro, A. (2002) The investor recognition hypothesis in a dynamic general equilibrium: theory and evidence, Review of Financial Studies 15, 97-141.

Siniscalchi, M. (2006) Dynamic choice under ambiguity, Discussion Paper 1366, Center for Mathematical Studies in Economics and Management Science, Northwestern University.

Tallon, J.- M. (1998) Asymmetric information, non-additive expected utility and the information revealed by prices: an example, International Economic Review 39, 329342.

Uppal, R. and Wang, T. (2003) Model misspecification and underdiversification, Journal of Finance 58, 2437-2464.

Vissing-Jorgensen, A. (2002) Limited asset market participation and the elasticity of intertemporal substitution, Journal of Political. Economy 110, 825-853.

Wakai, K. (2002) Linking behavioral economics, axiomatic decision theory and general equilibrium theory, Ph.D. dissertation, Yale University.

Wang, T. (2003) Conditional preferences and updating, Journal of Economic Theory 108, 286-321.

Wasserman, L. A. and Kadane, J. B. (1990) Bayes' theorem for Choquet capacities, Annals of Statistics 18, 1328-1339. 